\title{
Friedel-Crafts addition of indoles to nitrones promoted by trimethylsilyl
} trifluoromethanesulfonate

Zachary Z. Oracheff, Helen L. Xia, Christopher D. Poff, Scott E. Isaacson, and C. Wade Downey*

Supporting information: ${ }^{1} \mathrm{H}$ and ${ }^{13} \mathrm{C}$ NMR data for compounds 3a-16, table of comparison of promoting agents

Table of Contents

1. Table S1: Comparison of Promoting Agents

S 1

2. ${ }^{1} \mathrm{H}$ and ${ }^{13} \mathrm{C}$ NMR Spectra of Compounds $\mathbf{3 a}-\mathbf{8}$

S 3

3. ${ }^{1} \mathrm{H}$ and ${ }^{13} \mathrm{C}$ NMR Spectra of Compounds $9-18$

S 23 
Table S1: Comparison of Promoting Agents

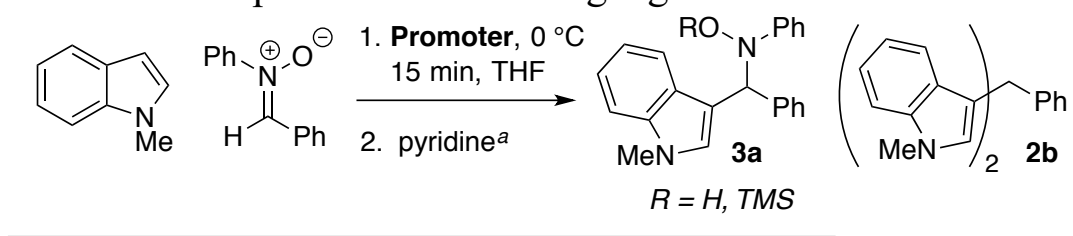

\begin{tabular}{ccccc}
\hline entry & Promoter & Additive & $\mathbf{3 a : 2 \mathbf { b } ^ { b }}$ & conv $(\%)^{b}$ \\
\hline 1 & TMSOTf & $i$-Pr ${ }_{2} \mathrm{NEt}$ & $100: 0$ & 100 \\
2 & $\mathrm{TMSOTf}$ & none & $0: 100$ & 100 \\
3 & $\mathrm{TMSCl}$ & pyridine & $0: 100$ & 45 \\
4 & $\mathrm{Zn}(\mathrm{OTf})_{2}$ & $i$-Pr ${ }_{2} \mathrm{NEt}$ & $0: 100$ & 100 \\
5 & $\mathrm{Zn}(\mathrm{OTf})_{2}$ & none & $0: 100$ & 100 \\
6 & $\mathrm{Fe}(\mathrm{OTf})_{3}$ & $i$-Pr ${ }_{2} \mathrm{NEt}$ & $0: 100$ & 80 \\
7 & $\mathrm{Fe}(\mathrm{OTf})_{3}$ & none & $0: 100$ & 100 \\
8 & $\mathrm{HCl}$ & none & $0: 100$ & $35^{c}$ \\
\hline
\end{tabular}

${ }^{a}$ Reaction conditions: $1.0 .20 \mathrm{mmol} N$-methylindole, $0.22 \mathrm{mmol} N$, $\alpha$-diphenylnitrone, 0.24 mmol promoter, 0.26 mmol additive, 1.0 $\mathrm{mL}$ THF, $0{ }^{\circ} \mathrm{C}, 15 \mathrm{~min}$. 2. $0.52 \mathrm{mmol}$ pyridine. ${ }^{b}$ Determined by ${ }^{1} \mathrm{H}$ NMR analysis of unpurified reaction mixture. ${ }^{c}$ Reaction performed in $\mathrm{MeOH}$ for $1 \mathrm{~h}$. 
3a

${ }_{\mathrm{h} x}^{1} \mathrm{H}$ NMR 77 itr-3.10 (40 $400 \mathrm{MHz}, \mathrm{CD}_{2} \mathrm{Cl}_{2}$ )

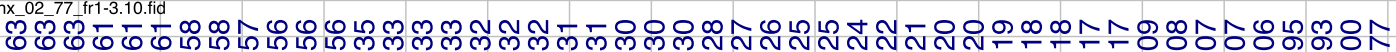

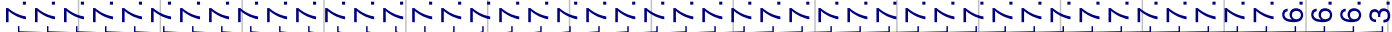






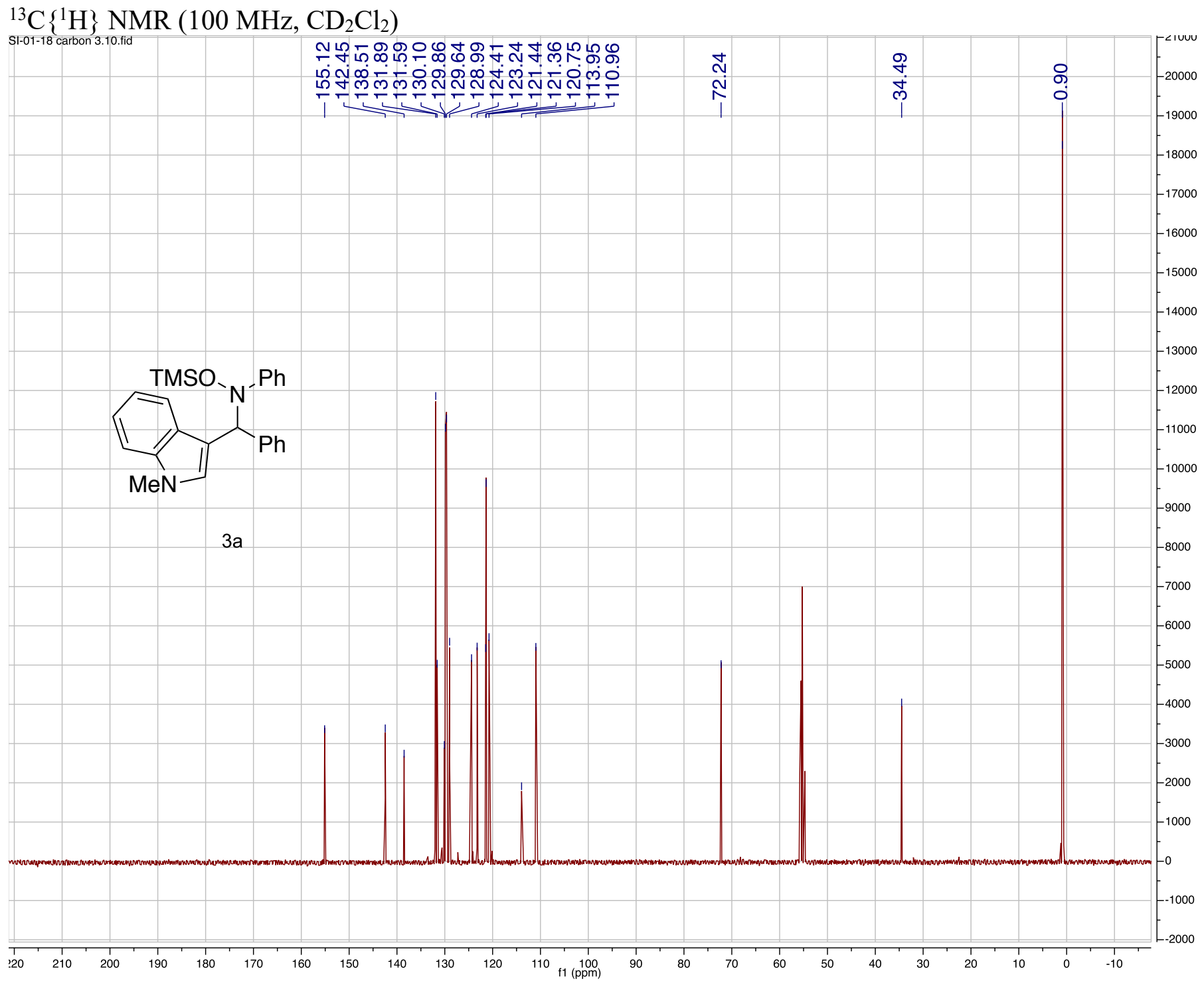


3b

${ }^{1} \mathrm{H}$ NMR $\left(500 \mathrm{MHz}, \mathrm{CD}_{2} \mathrm{Cl}_{2}\right)$

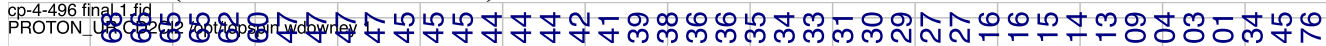

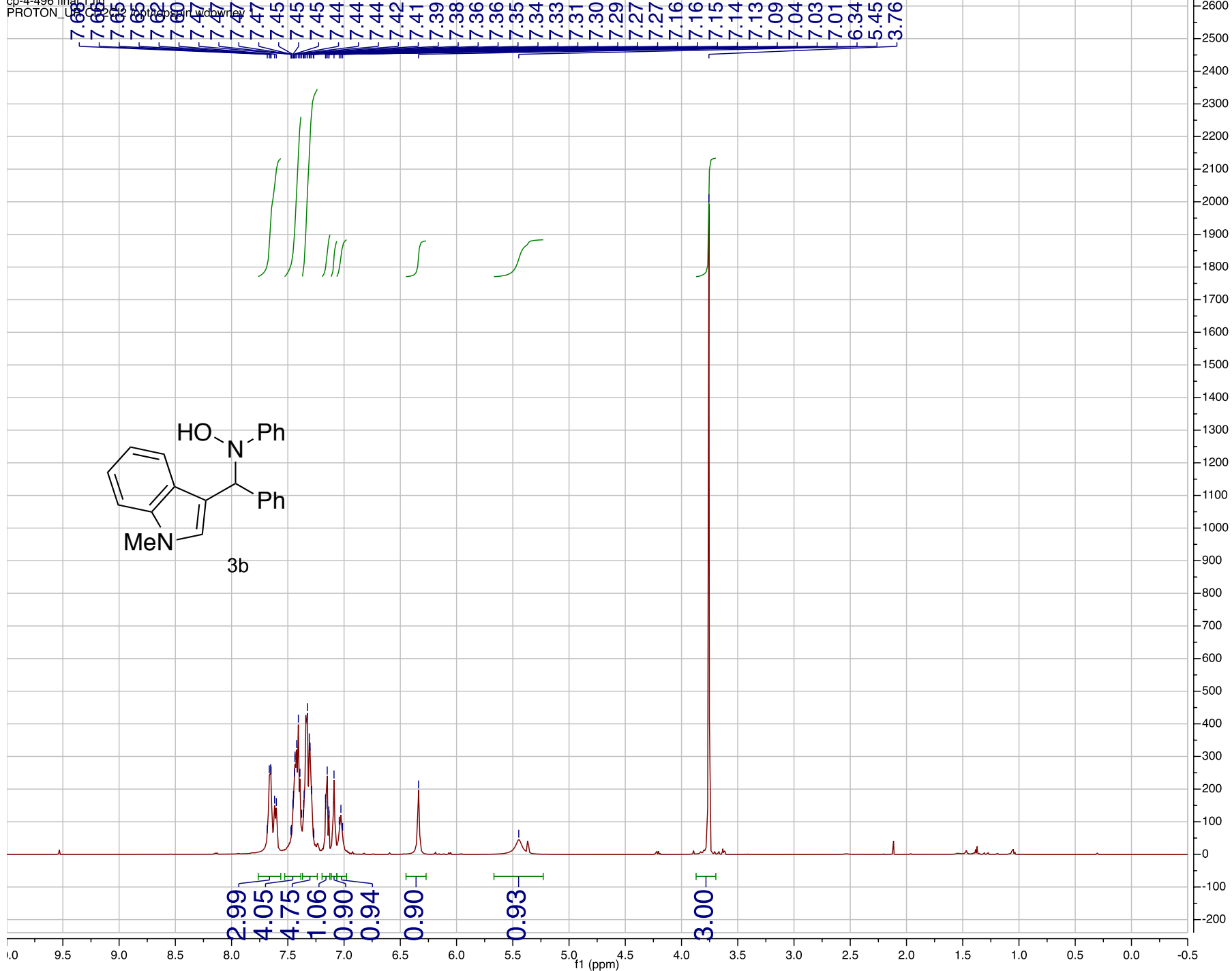




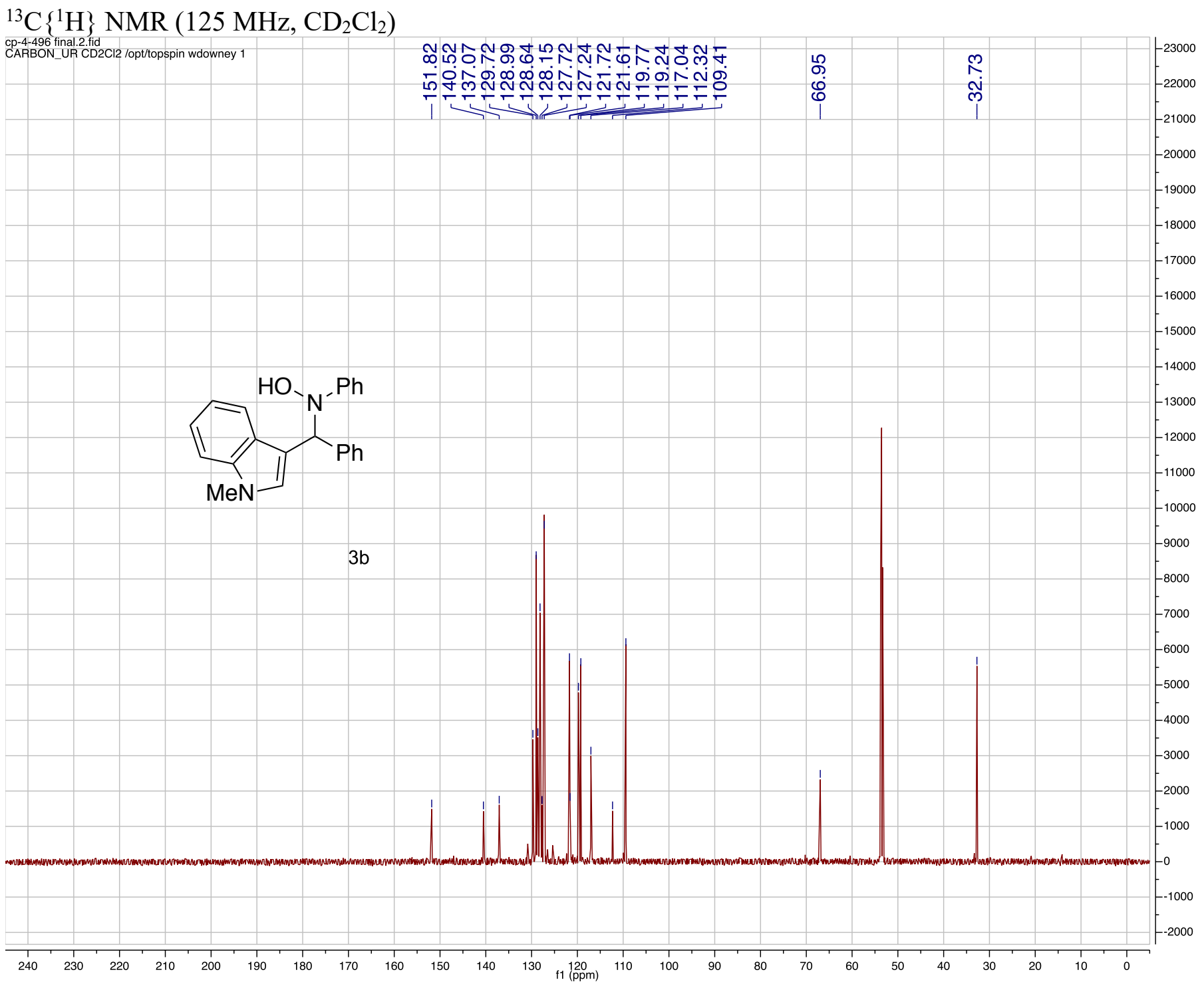


$3 c$

${ }^{1} \mathrm{H}$ NMR (400 MHz, $\mathrm{CD}_{2} \mathrm{Cl}_{2}$ )

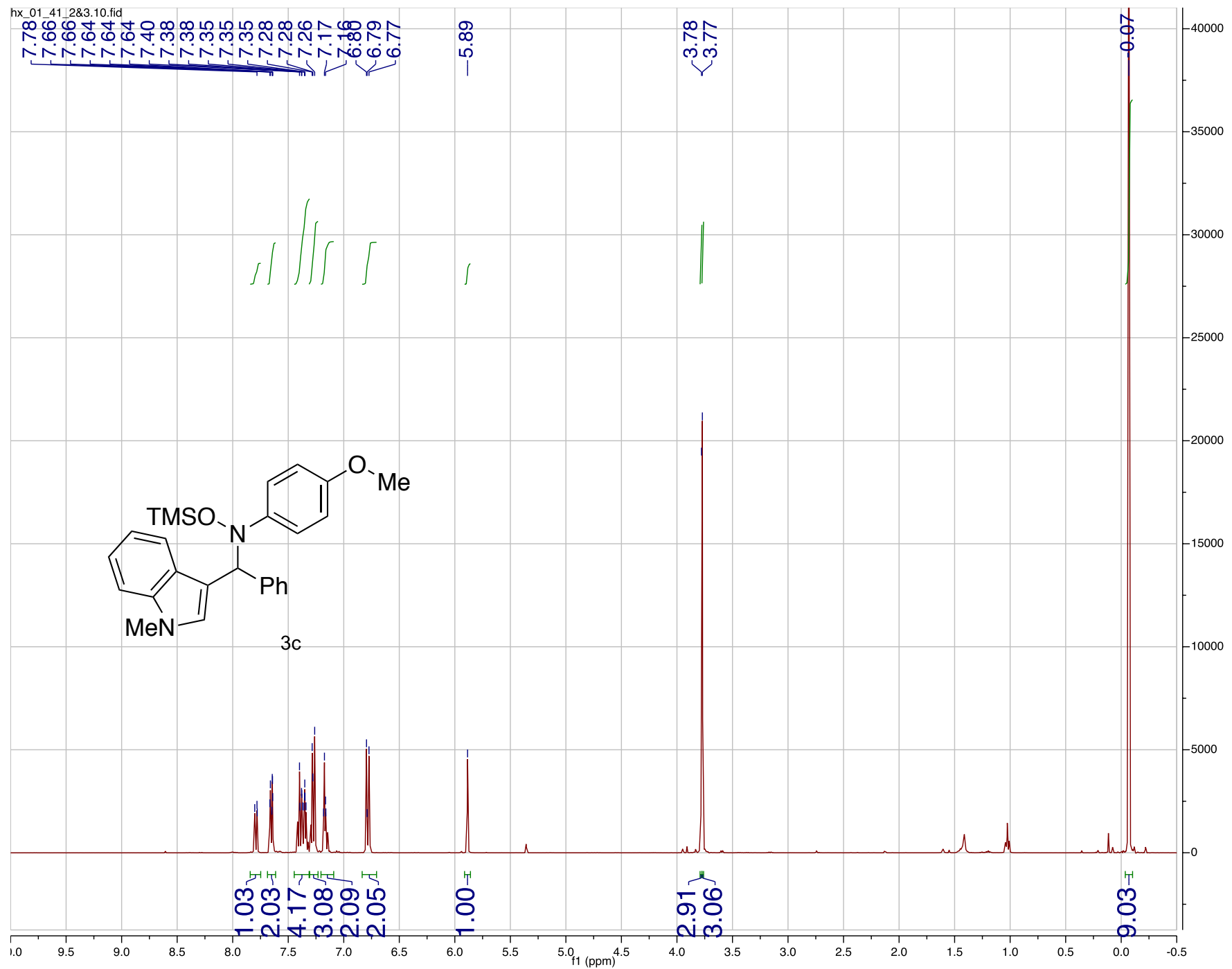


${ }^{13} \mathrm{C}\left\{{ }^{1} \mathrm{H}\right\}$ NMR $\left(100 \mathrm{MHz}, \mathrm{CD}_{2} \mathrm{Cl}_{2}\right)$

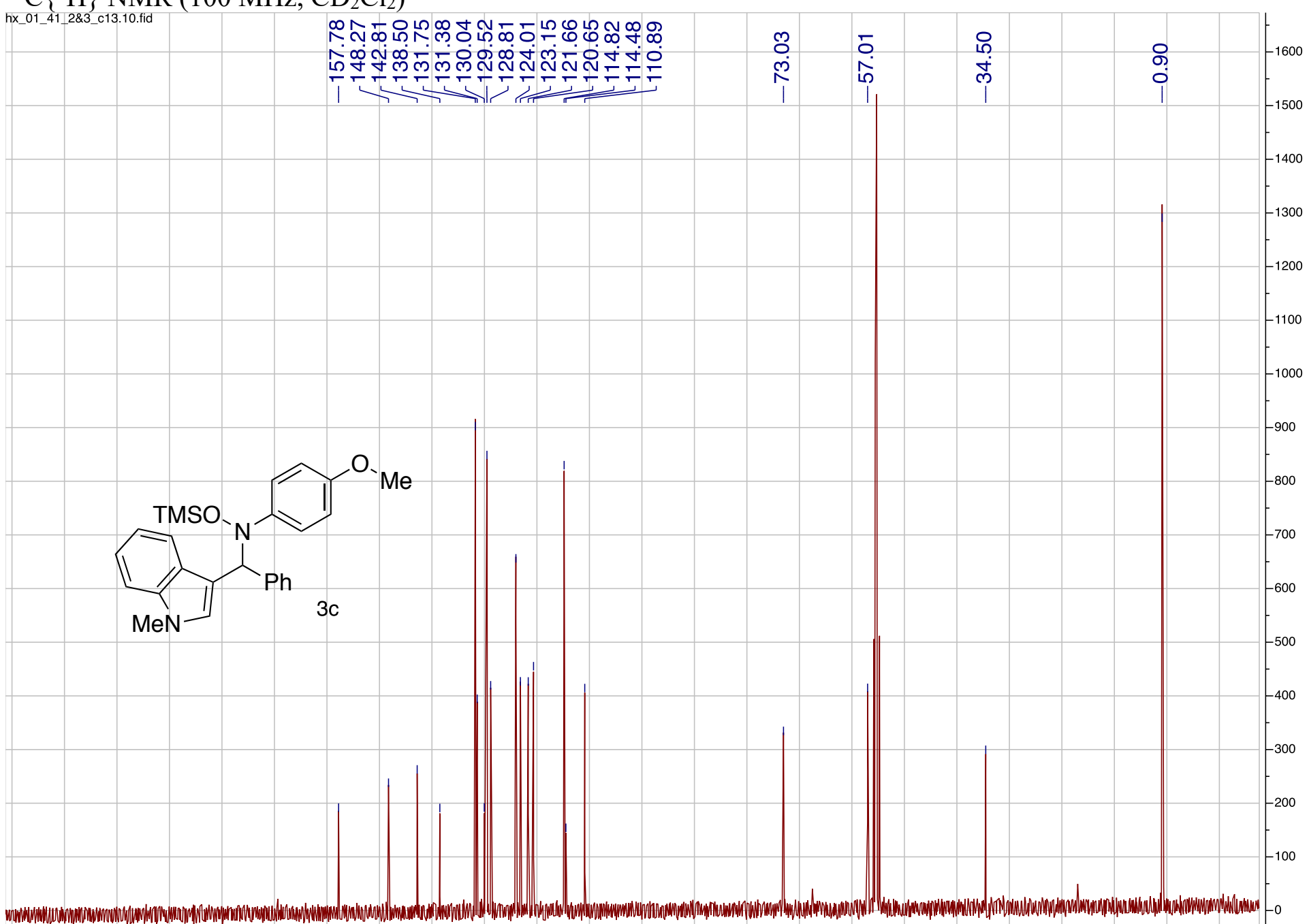

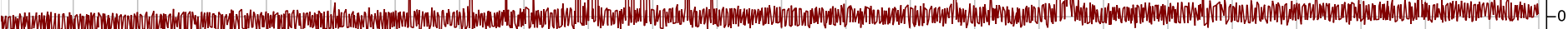
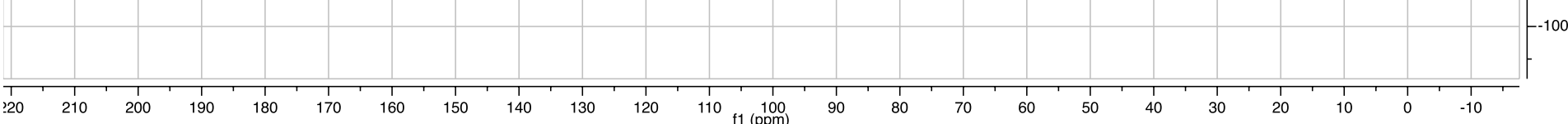

100 
3d

${ }^{1} \mathrm{H}$ NMR (500 MHz, $\mathrm{CD}_{2} \mathrm{Cl}_{2}$ )

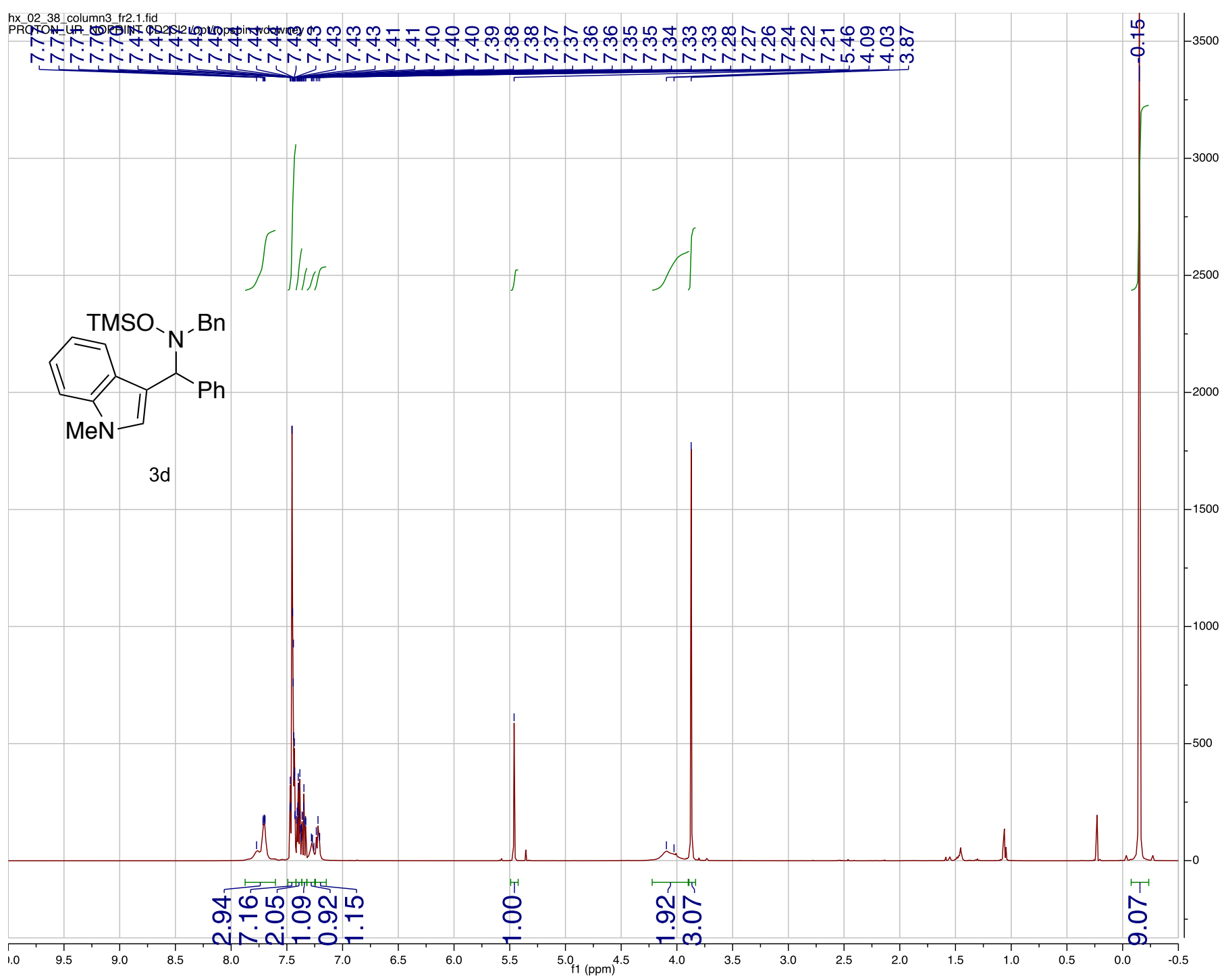


${ }^{13} \mathrm{C}\left\{{ }^{1} \mathrm{H}\right\}$ NMR $\left(125 \mathrm{MHz}, \mathrm{CD}_{2} \mathrm{Cl}_{2}\right)$

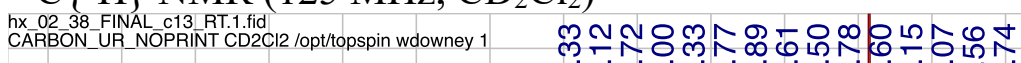

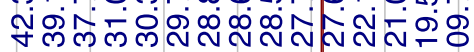

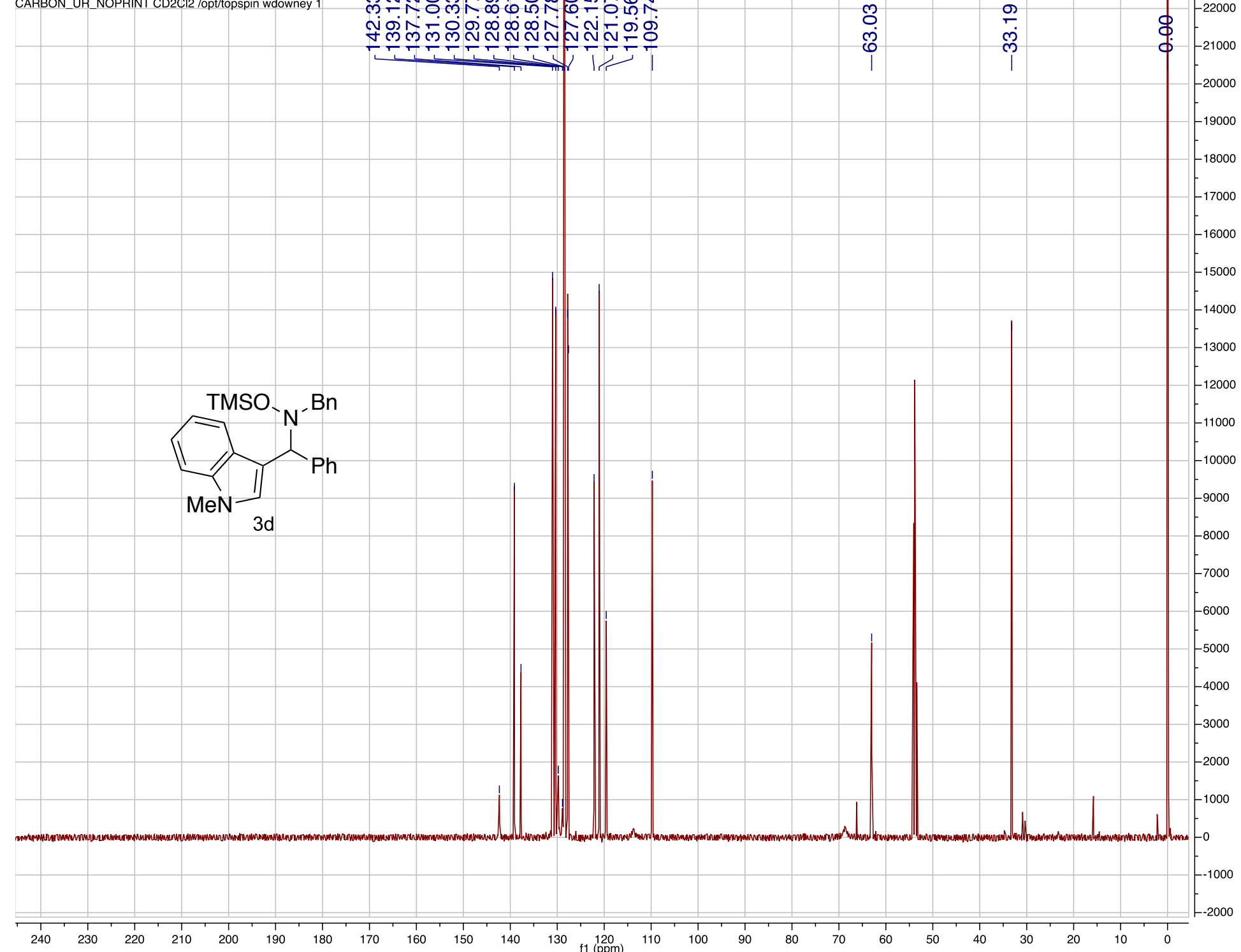


$3 \mathbf{e}$

${ }^{1} \mathrm{H}$ NMR $\left(400 \mathrm{MHz}, \mathrm{CD}_{2} \mathrm{Cl}_{2}\right.$ )

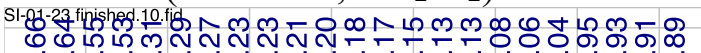

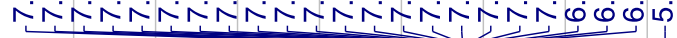
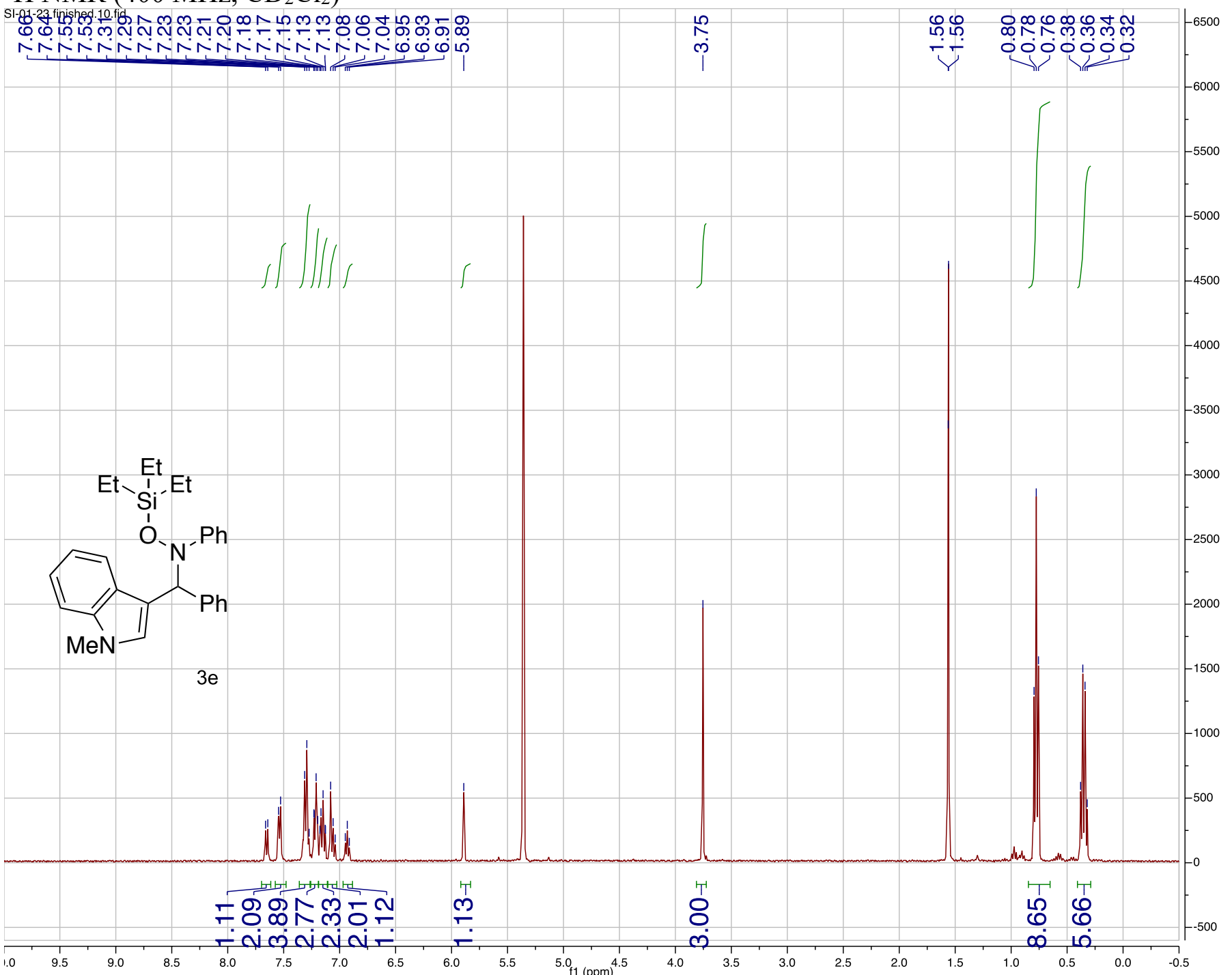
${ }^{13} \mathrm{C}\left\{{ }^{1} \mathrm{H}\right\}$ NMR $\left(100 \mathrm{MHz}, \mathrm{CD}_{2} \mathrm{Cl}_{2}\right)$

s1-01-23 finished carbon.10.fid Mํํำ

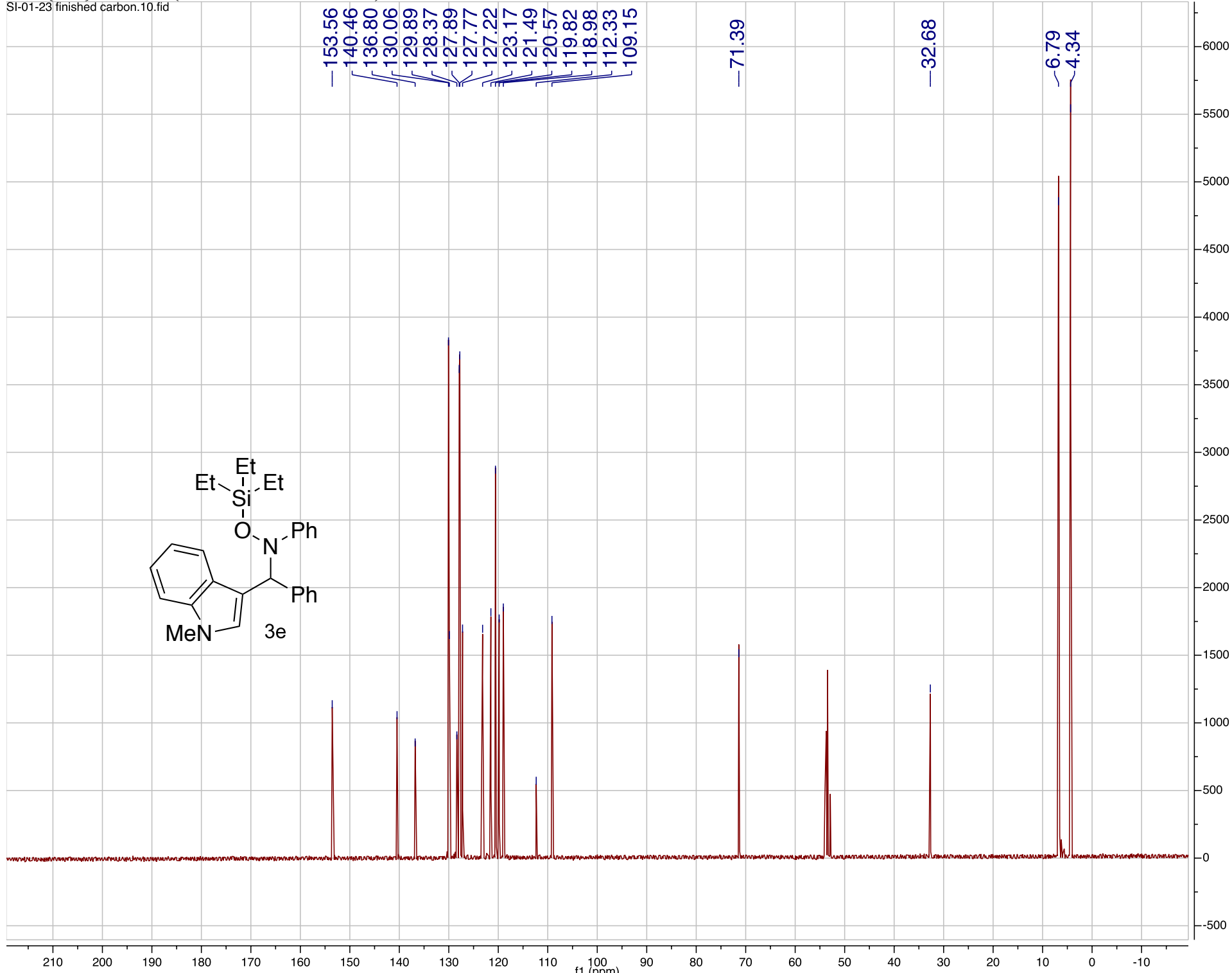


${ }^{1} \mathrm{H}$ NMR $\left(400 \mathrm{MHz}, \mathrm{CD}_{2} \mathrm{Cl}_{2}\right)$

S1-1-36 2-4.10.1d

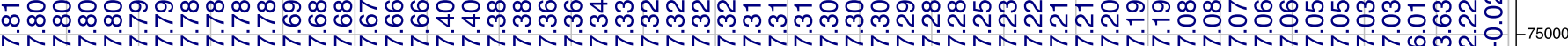

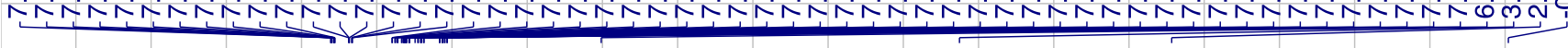

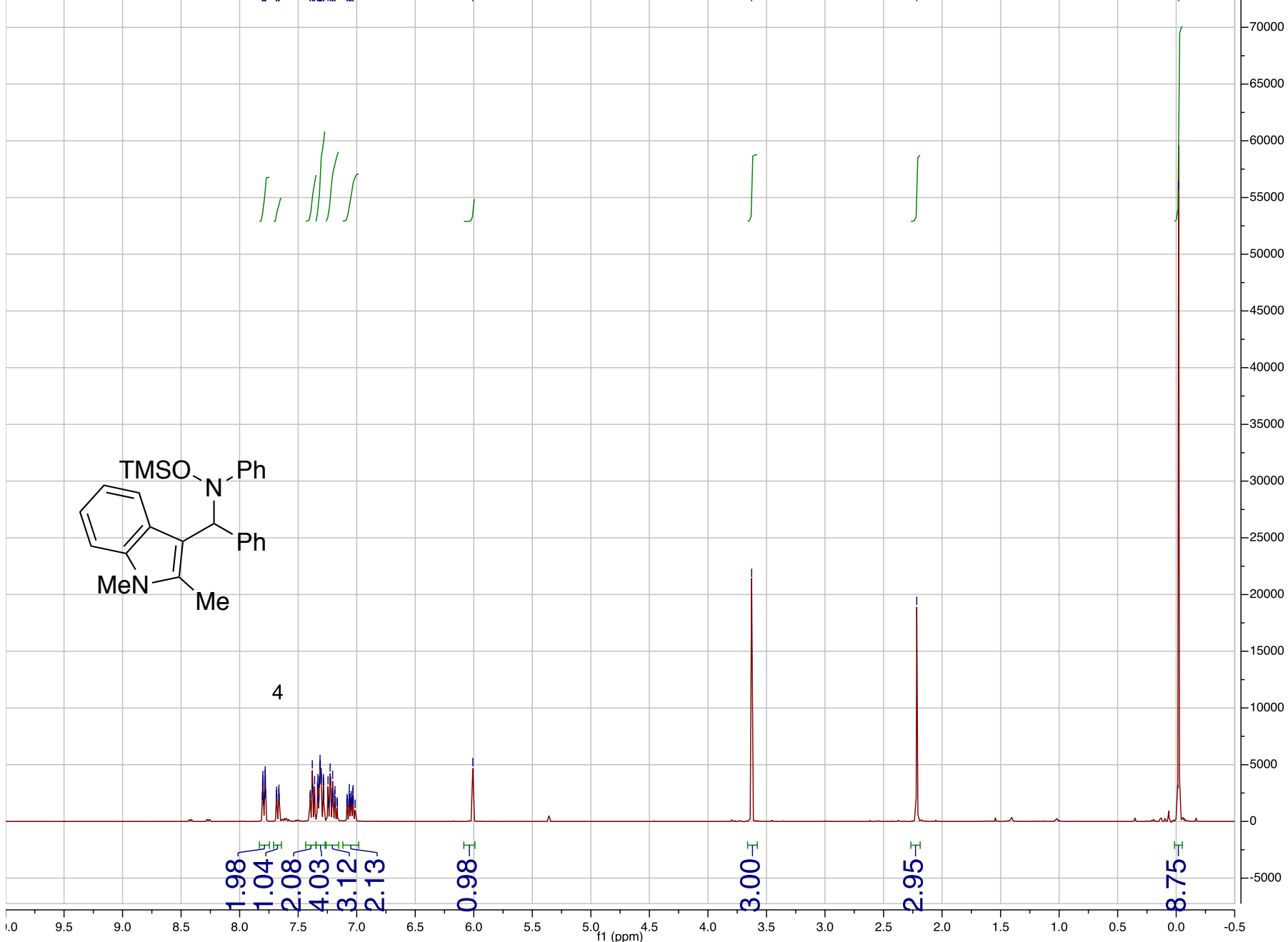


${ }^{13} \mathrm{C}\left\{{ }^{1} \mathrm{H}\right\}$ NMR $\left(100 \mathrm{MHz}, \mathrm{CD}_{2} \mathrm{Cl}_{2}\right)$

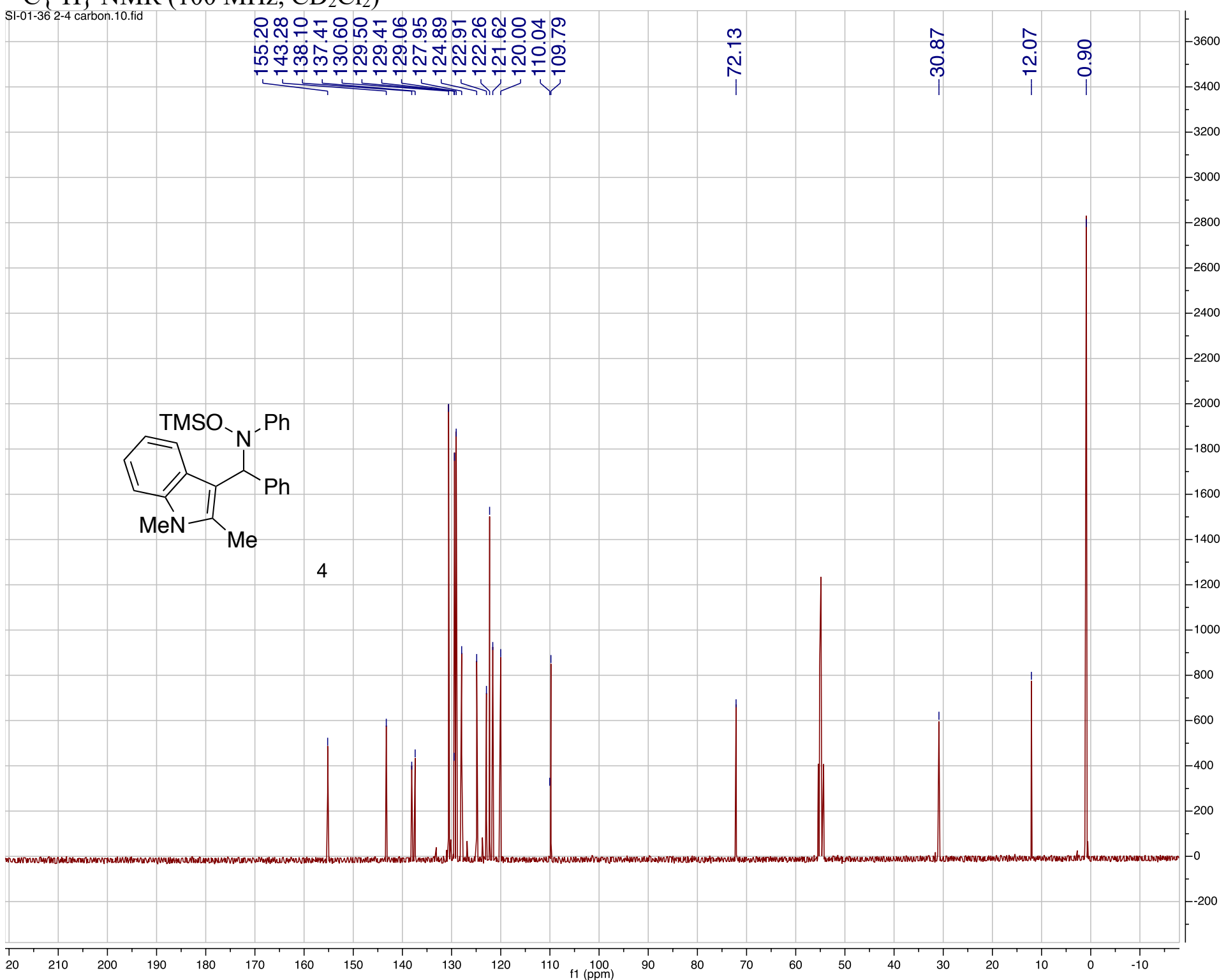


${ }^{1} \mathrm{H}$ NMR $\left(500 \mathrm{MHz}, \mathrm{CD}_{2} \mathrm{Cl}_{2}\right)$

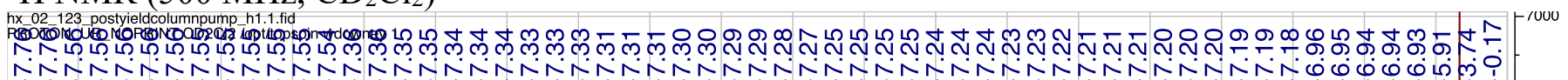
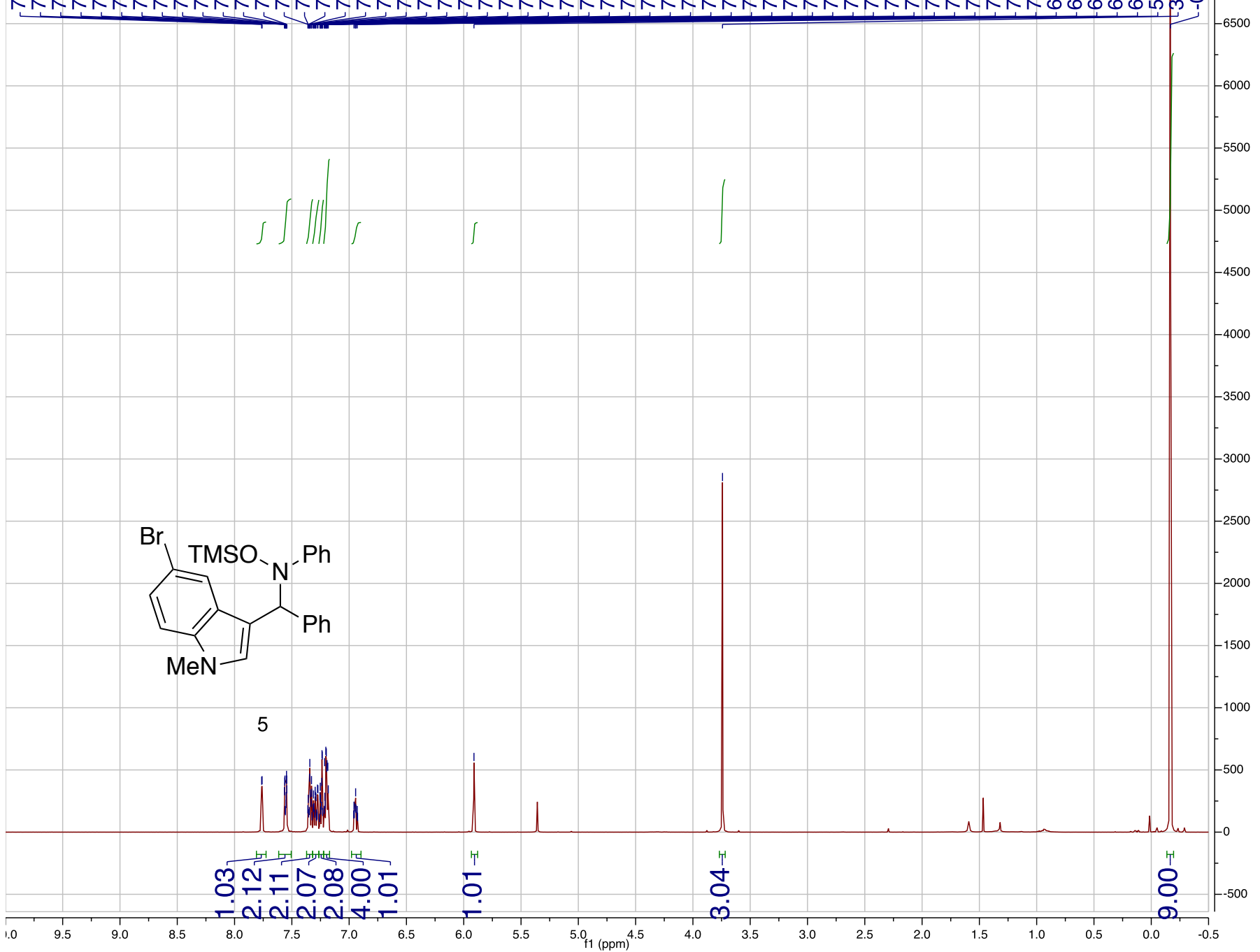


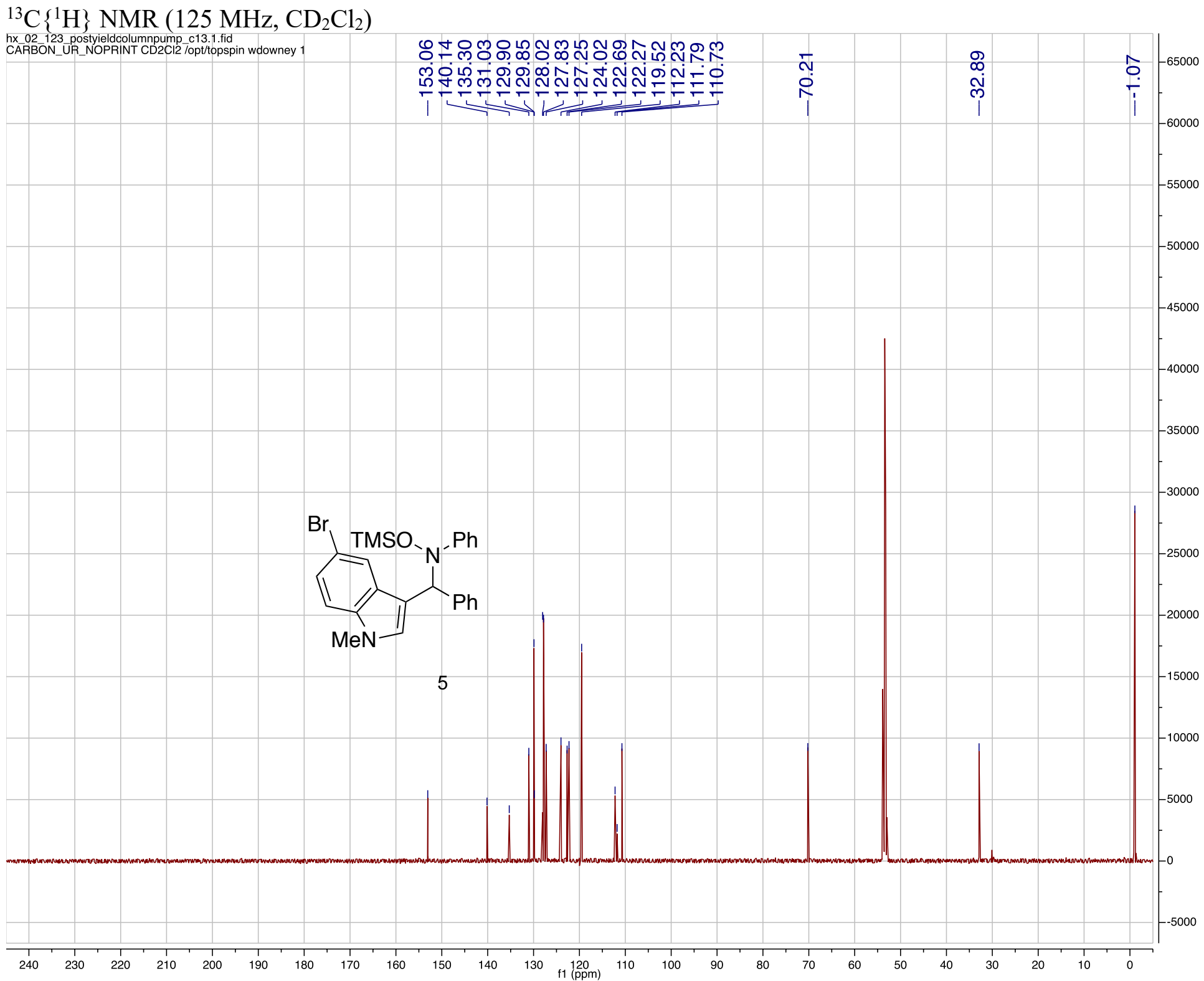


6

${ }^{1} \mathrm{H}$ NMR $\left(500 \mathrm{MHz}, \mathrm{CD}_{2} \mathrm{Cl}_{2}\right)$

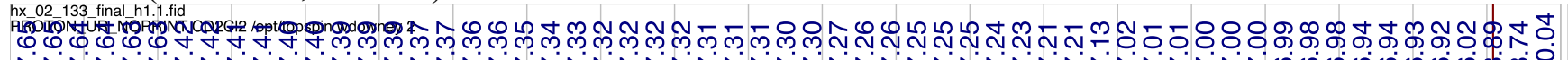

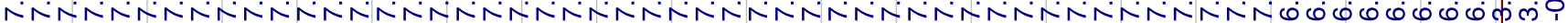
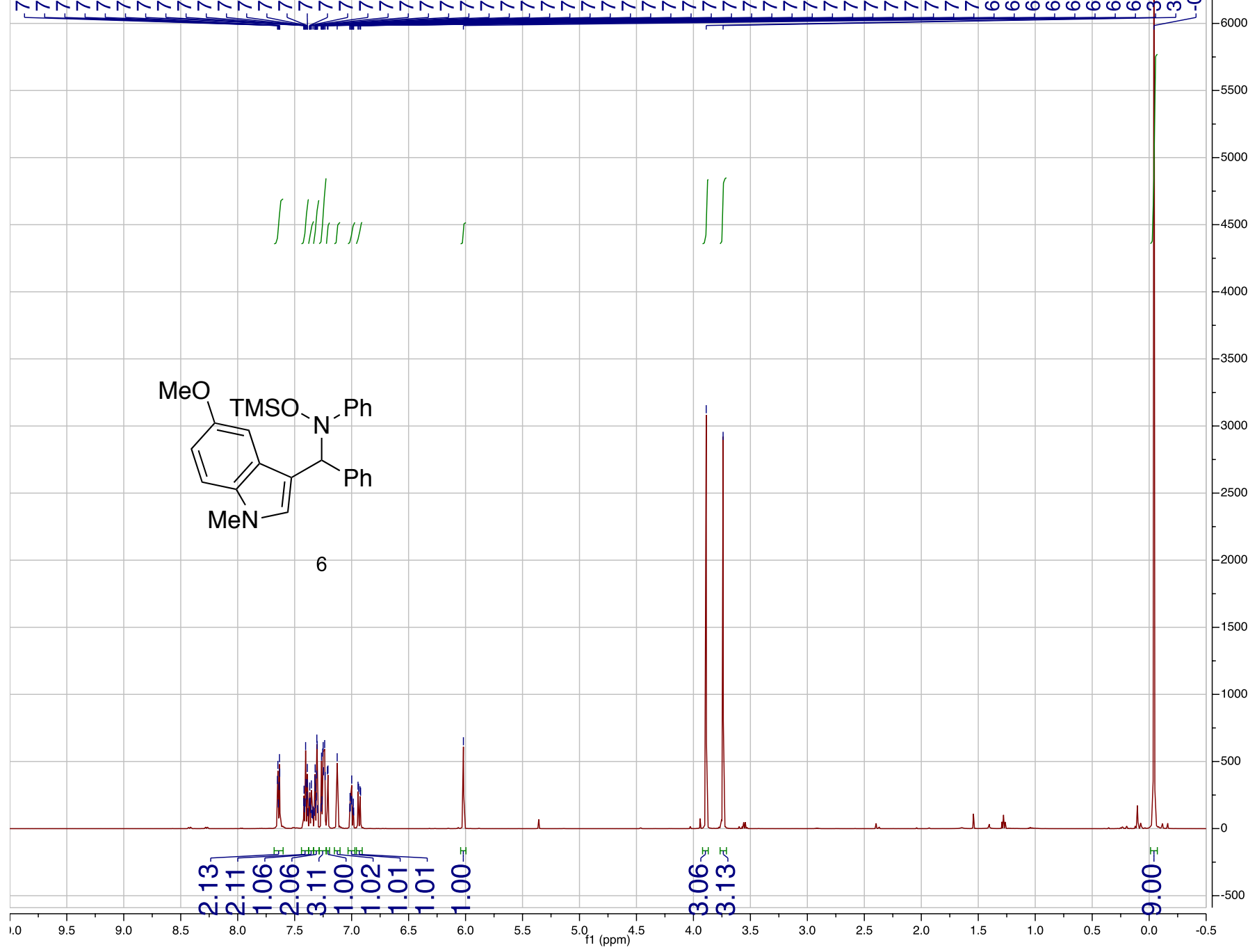
${ }^{13} \mathrm{C}\left\{{ }^{1} \mathrm{H}\right\} \mathrm{NMR}\left(125 \mathrm{MHz}, \mathrm{CD}_{2} \mathrm{Cl}_{2}\right)$

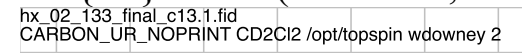

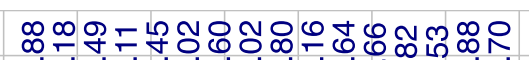

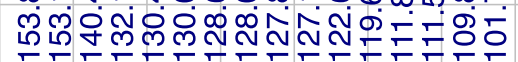

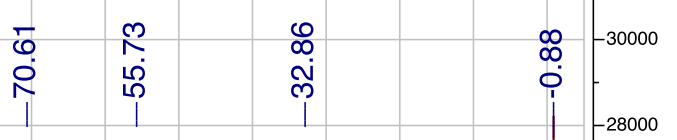

$\mathrm{MeO}$ $\mathrm{TMSO}_{-\mathrm{N}} \mathrm{TH}^{\mathrm{Ph}}$ MeN-

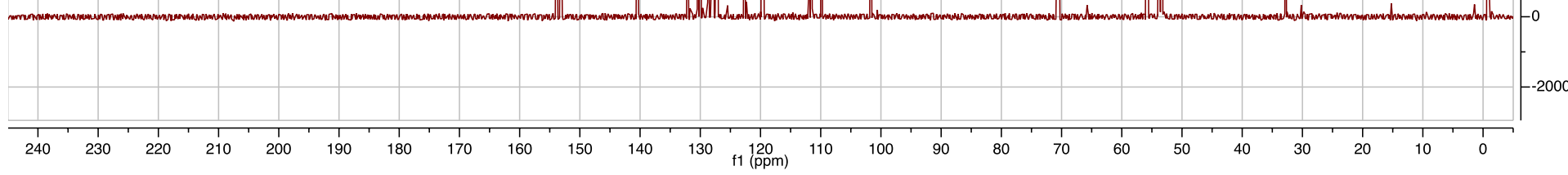

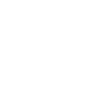


7

${ }^{1} \mathrm{H}$ NMR (400 MHz, $\left.\mathrm{CD}_{2} \mathrm{Cl}_{2}\right)$

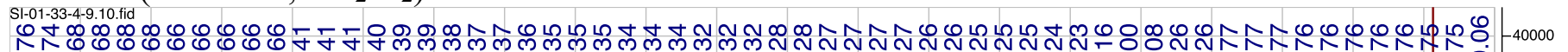

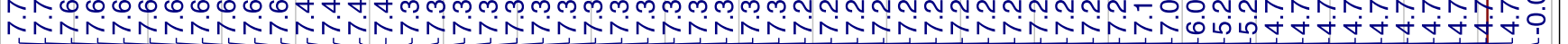

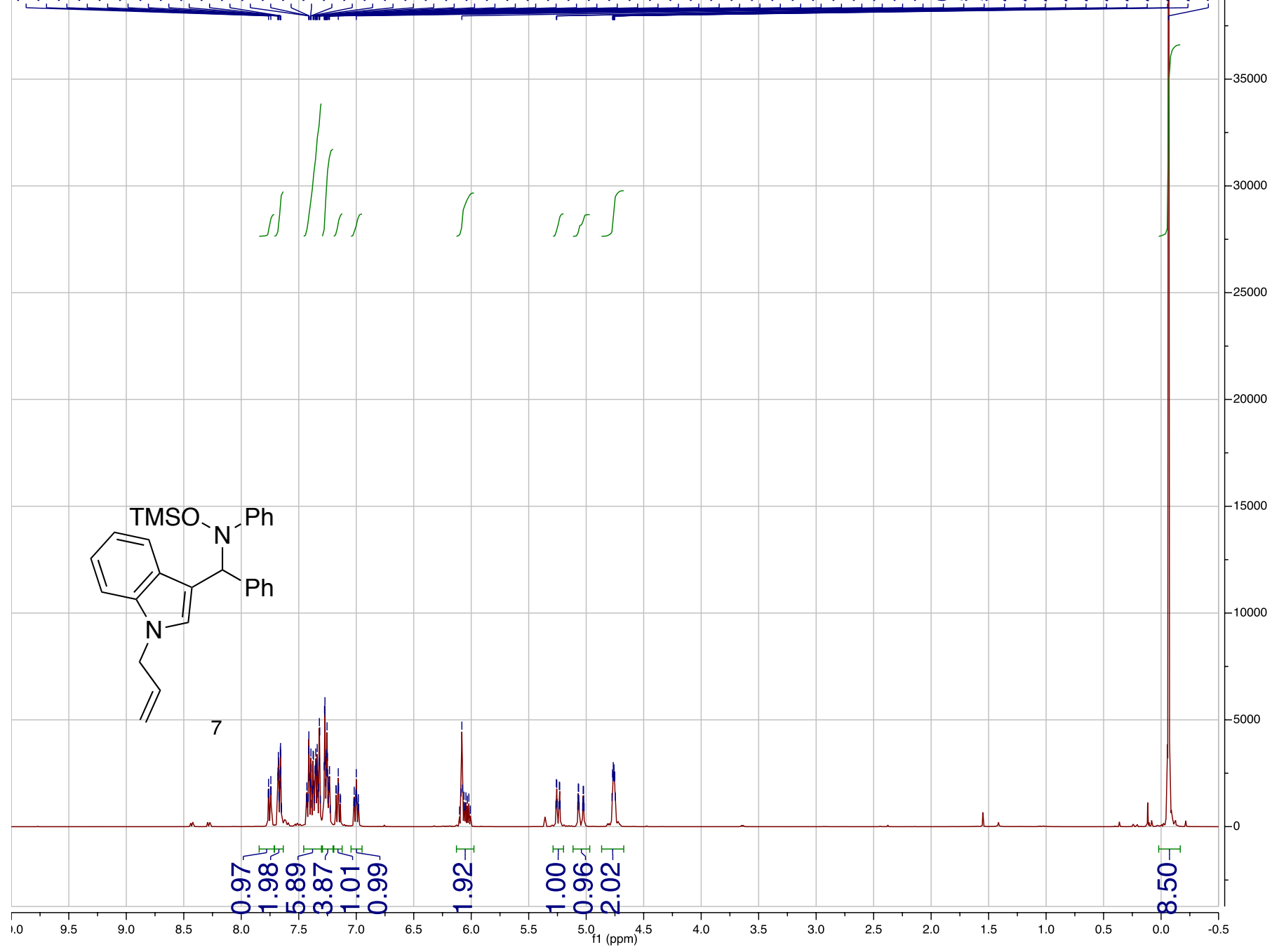




$$
\text { ili }
$$


8

${ }^{1} \mathrm{H}$ NMR $\left(500 \mathrm{MHz}, \mathrm{CD}_{2} \mathrm{Cl}_{2}\right)$

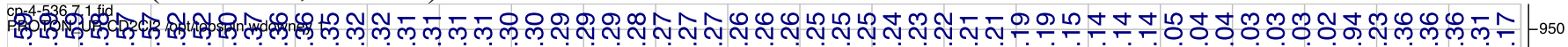

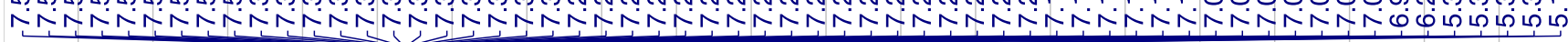

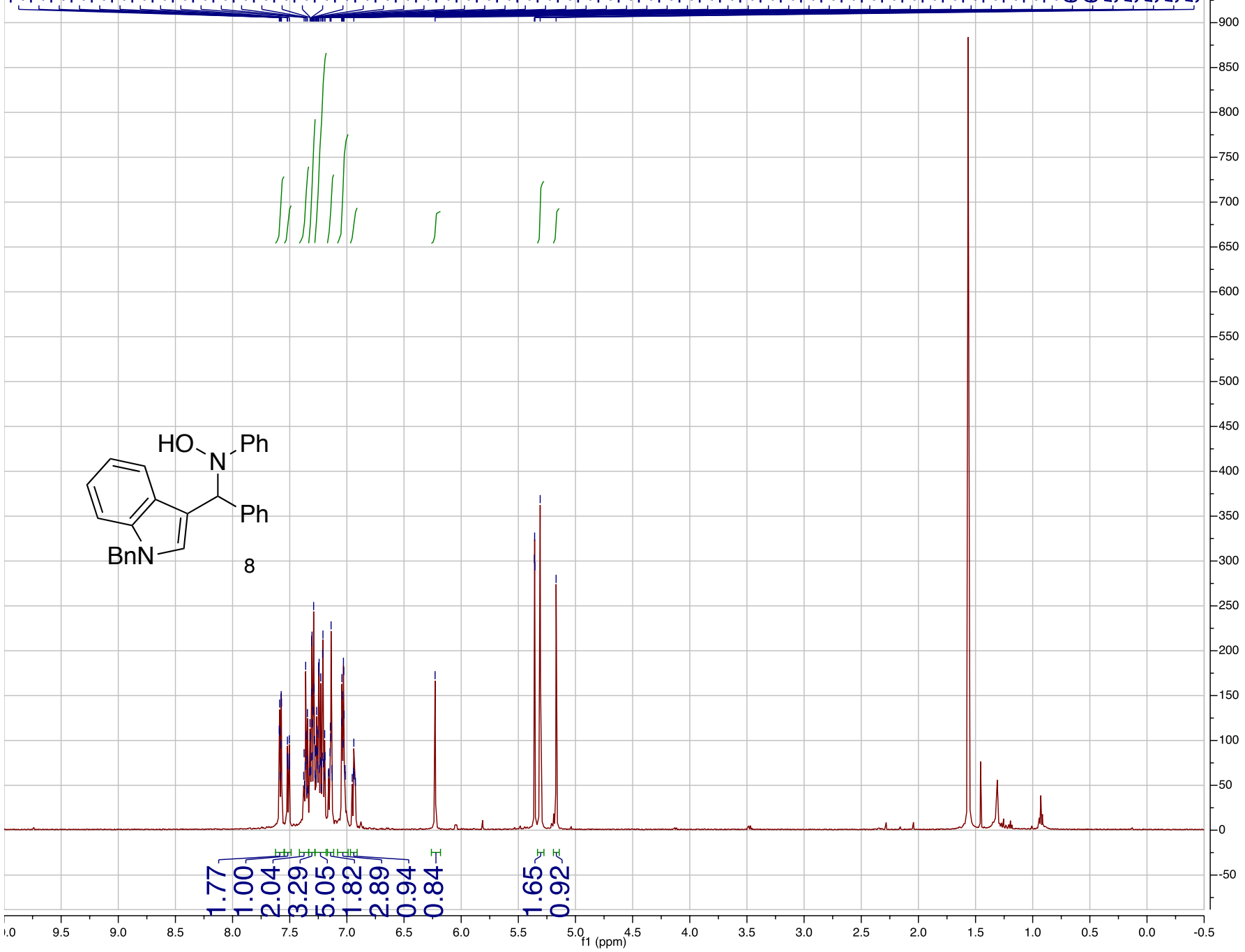


${ }^{13} \mathrm{C}\left\{{ }^{1} \mathrm{H}\right\} \mathrm{NMR}\left(125 \mathrm{MHz}, \mathrm{CD}_{2} \mathrm{Cl}_{2}\right)$

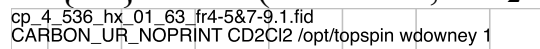

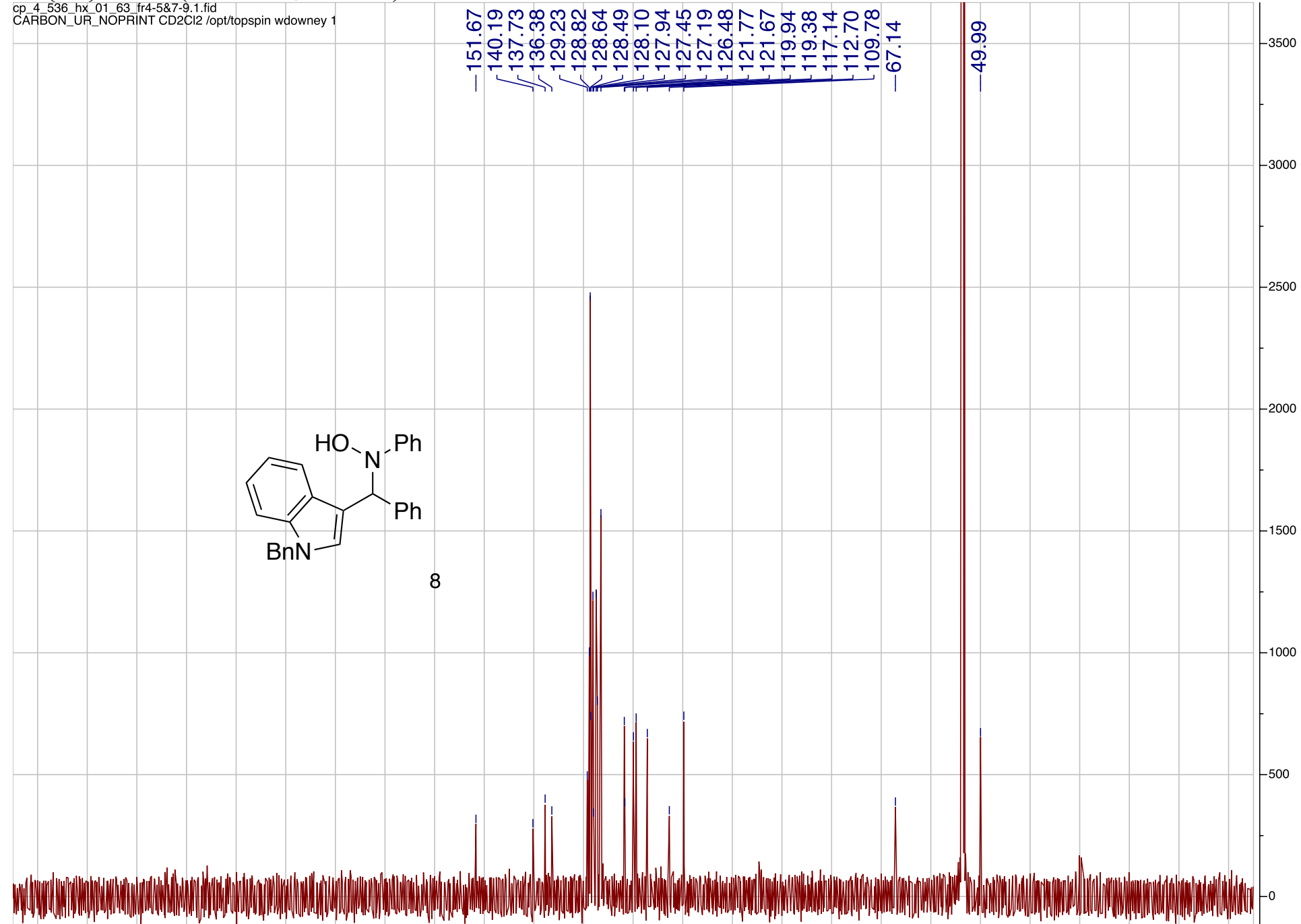

$\begin{array}{llllll}240 & 230 & 220 & 210 & 200 & 190\end{array}$

150

$\begin{array}{lll}30 & 120 \\ \mathrm{f} 1(\mathrm{ppm}) & 110 & 100\end{array}$

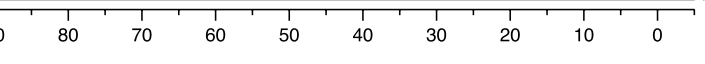


9

${ }^{1} \mathrm{H}$ NMR $\left(300 \mathrm{MHz}, \mathrm{CD}_{2} \mathrm{Cl}_{2}\right)$

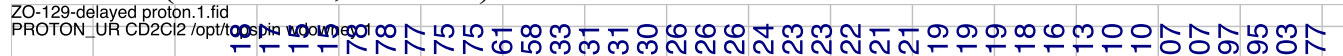

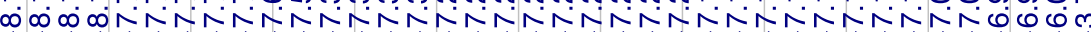

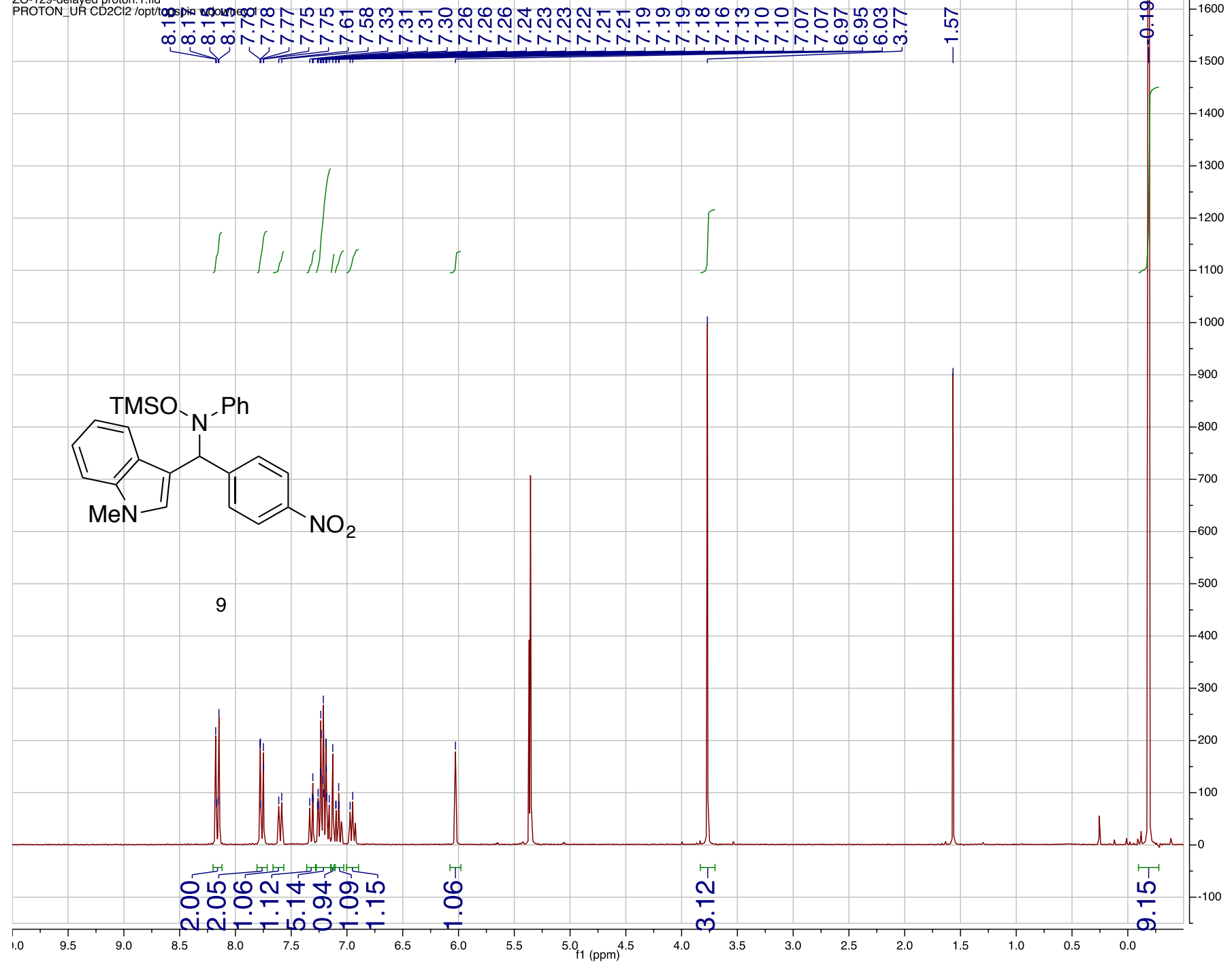


${ }^{13} \mathrm{C}\left\{{ }^{1} \mathrm{H}\right\} \mathrm{NMR}\left(125 \mathrm{MHz}, \mathrm{CD}_{2} \mathrm{Cl}_{2}\right)$

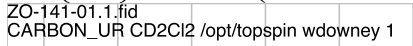

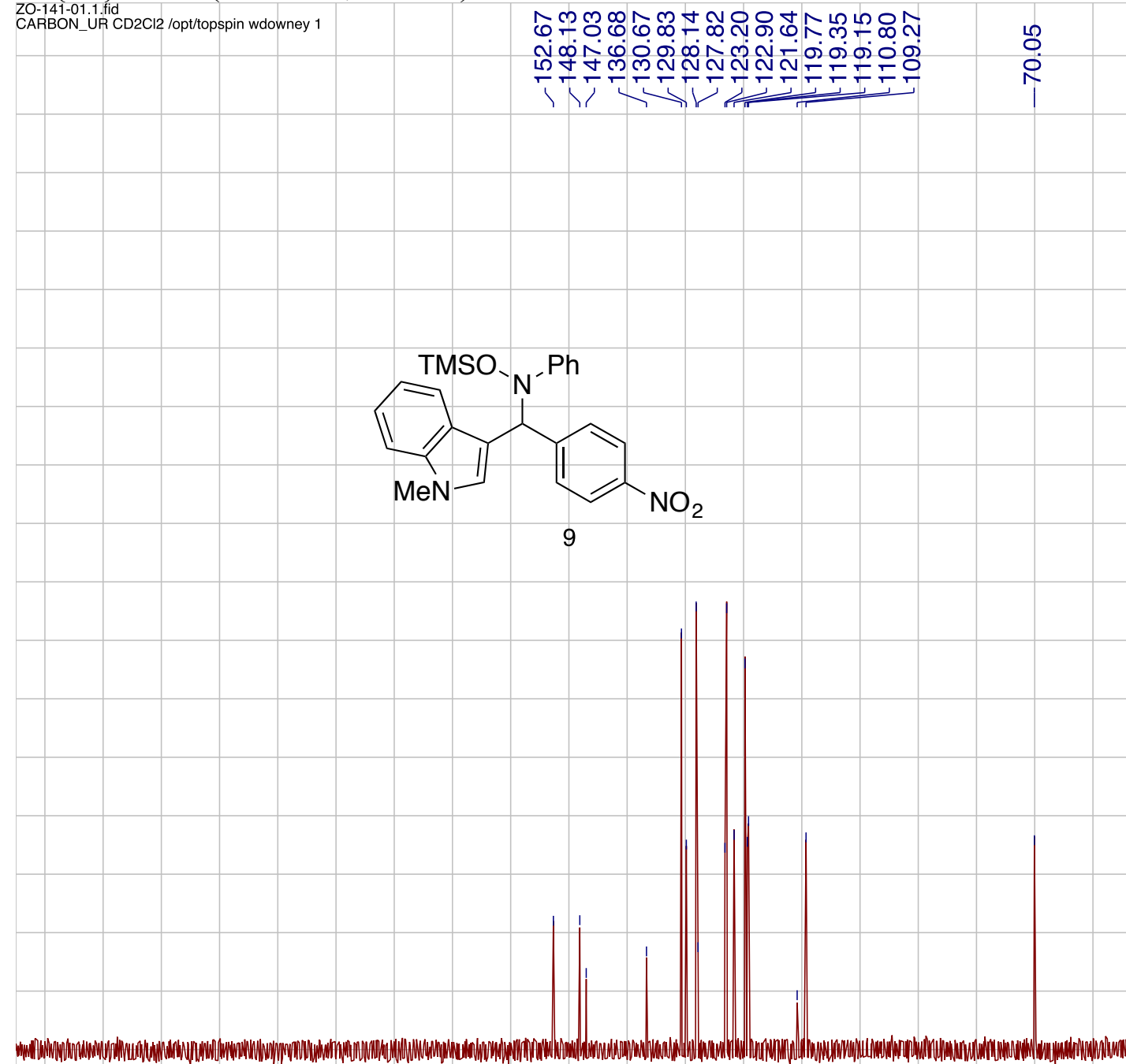

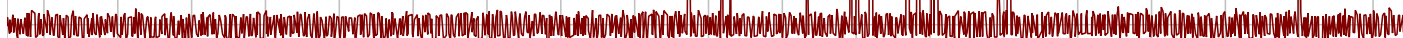

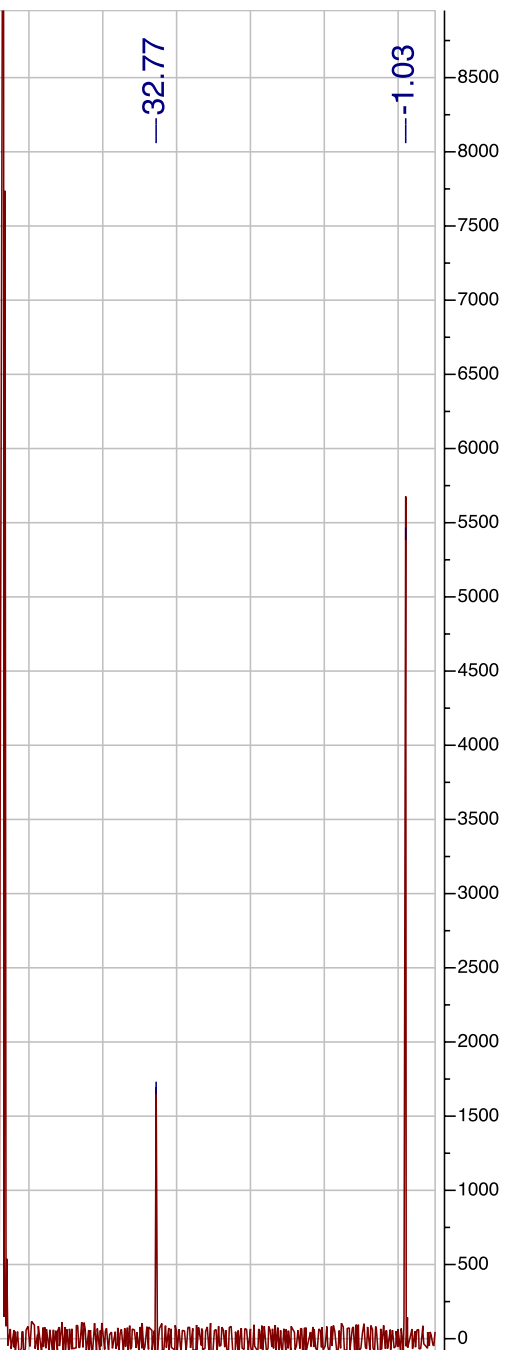

$-500$

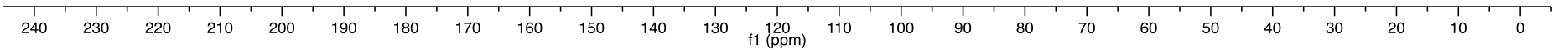


10

${ }^{1} \mathrm{H}$ NMR (300 MHz, $\left.\mathrm{CD}_{2} \mathrm{Cl}_{2}\right)$

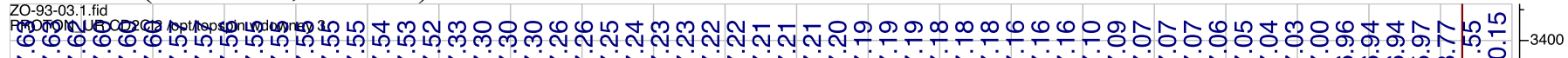

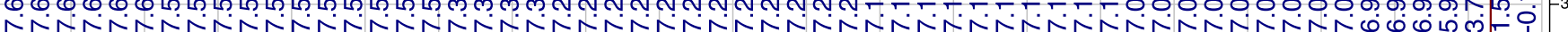
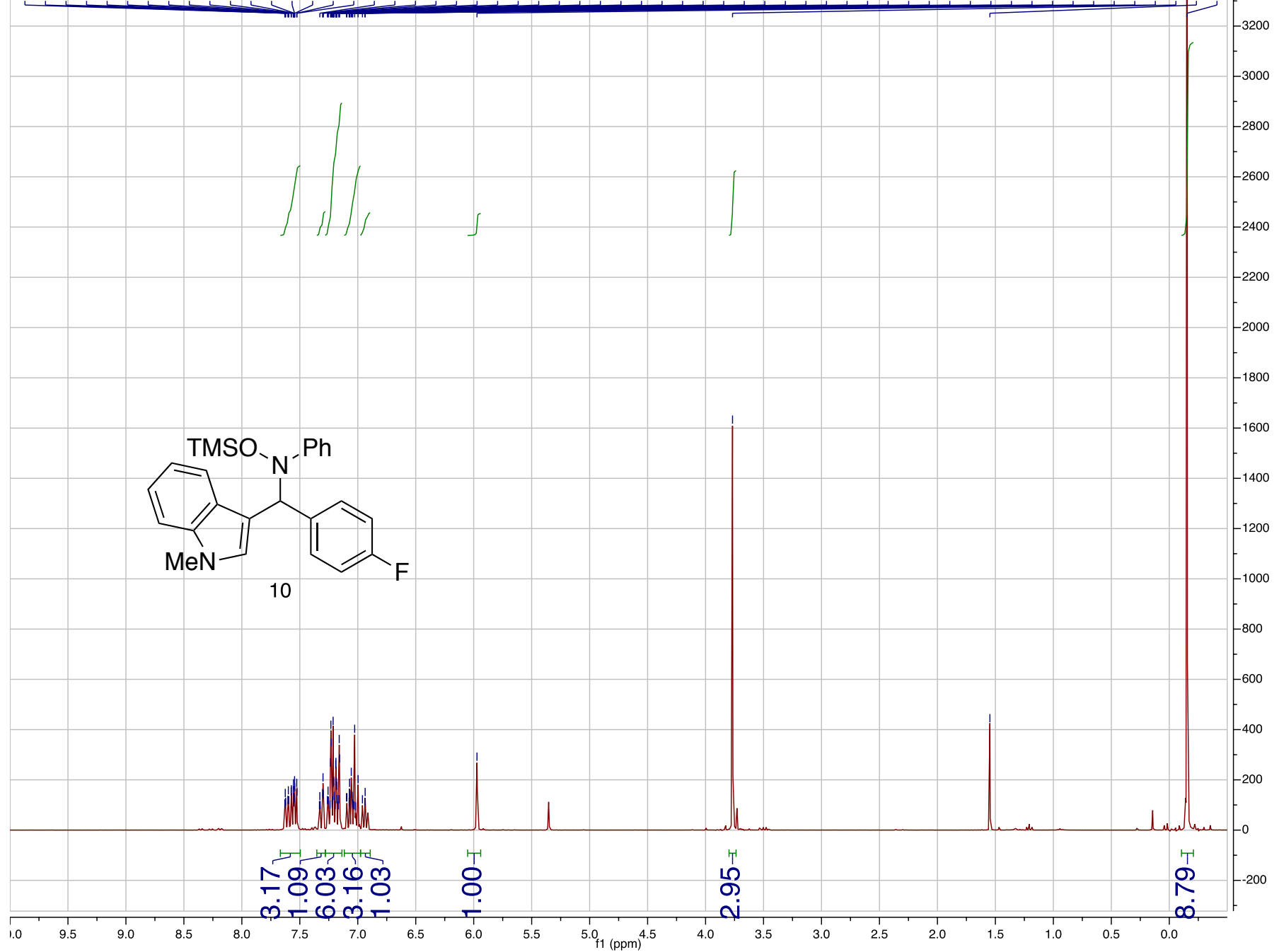
${ }^{13} \mathrm{C}\left\{{ }^{1} \mathrm{H}\right\} \mathrm{NMR}\left(125 \mathrm{MHz}, \mathrm{CD}_{2} \mathrm{Cl}_{2}\right)$
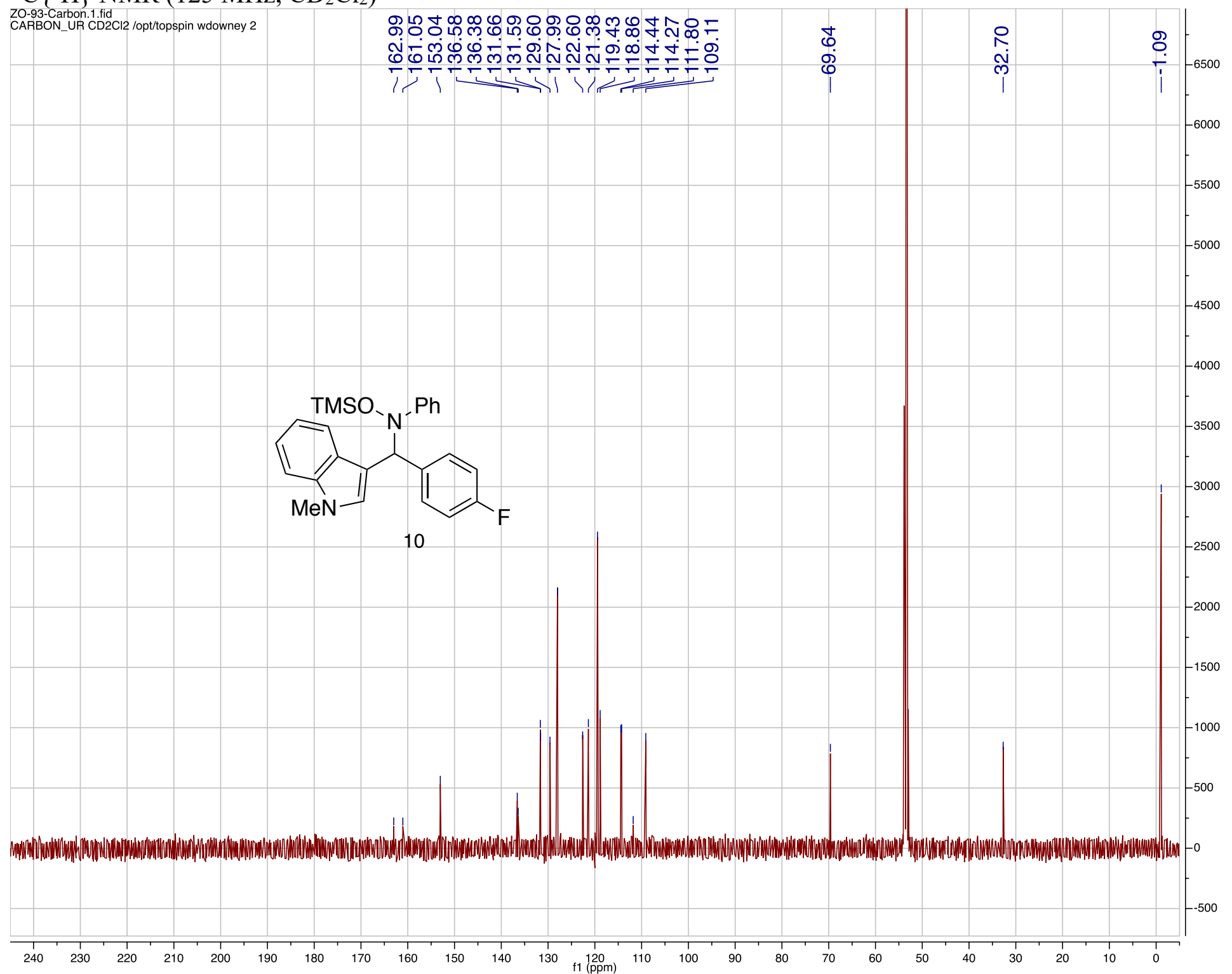
11

${ }^{1} \mathrm{H}$ NMR (500 MHz, $\mathrm{CD}_{2} \mathrm{Cl}_{2}$ )

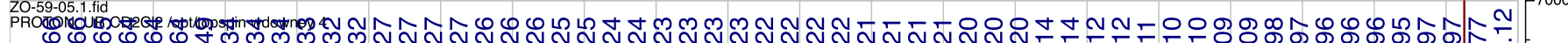

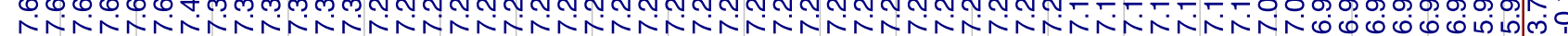

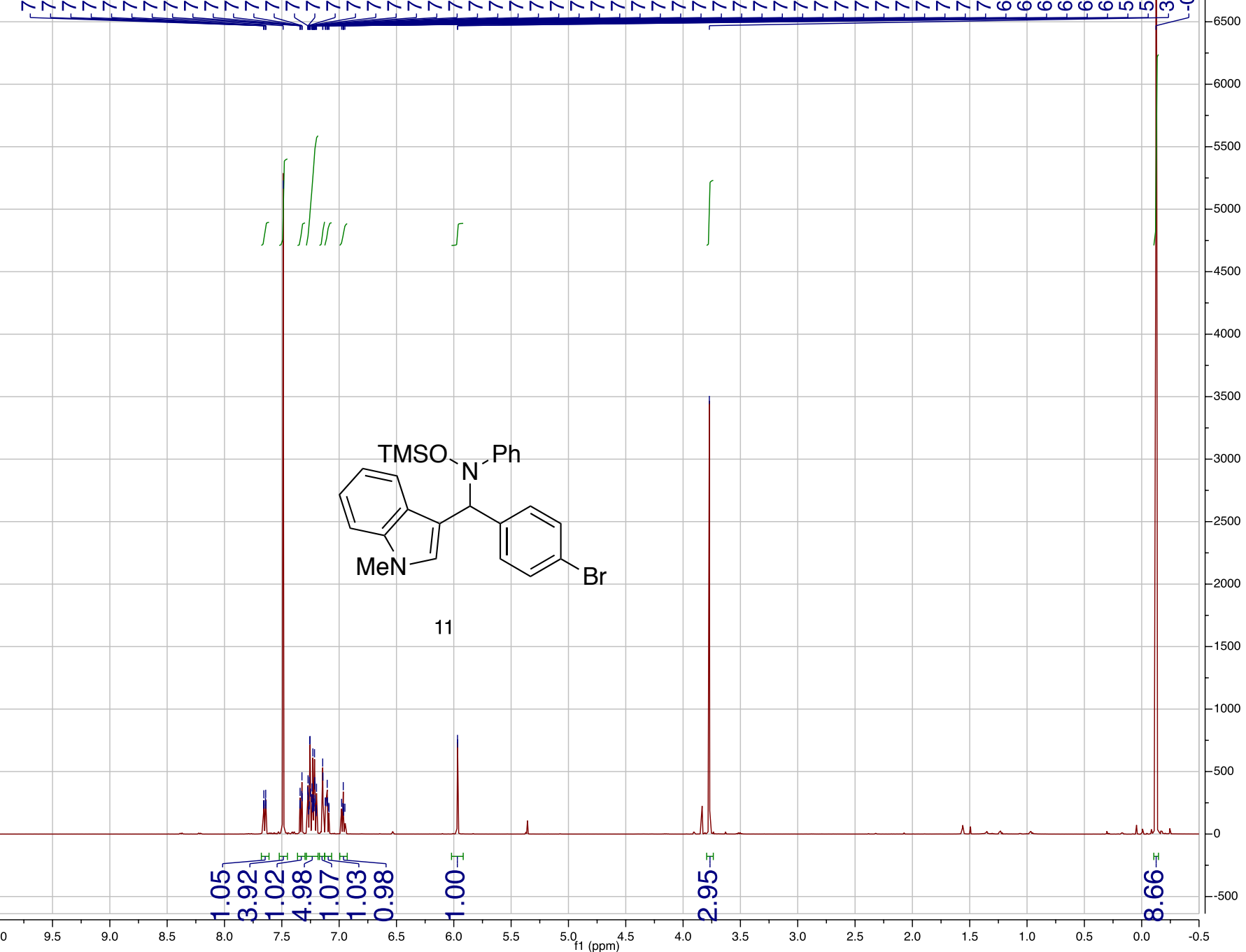


${ }^{13} \mathrm{C}\left\{{ }^{1} \mathrm{H}\right\} \mathrm{NMR}\left(125 \mathrm{MHz}, \mathrm{CD}_{2} \mathrm{Cl}_{2}\right)$

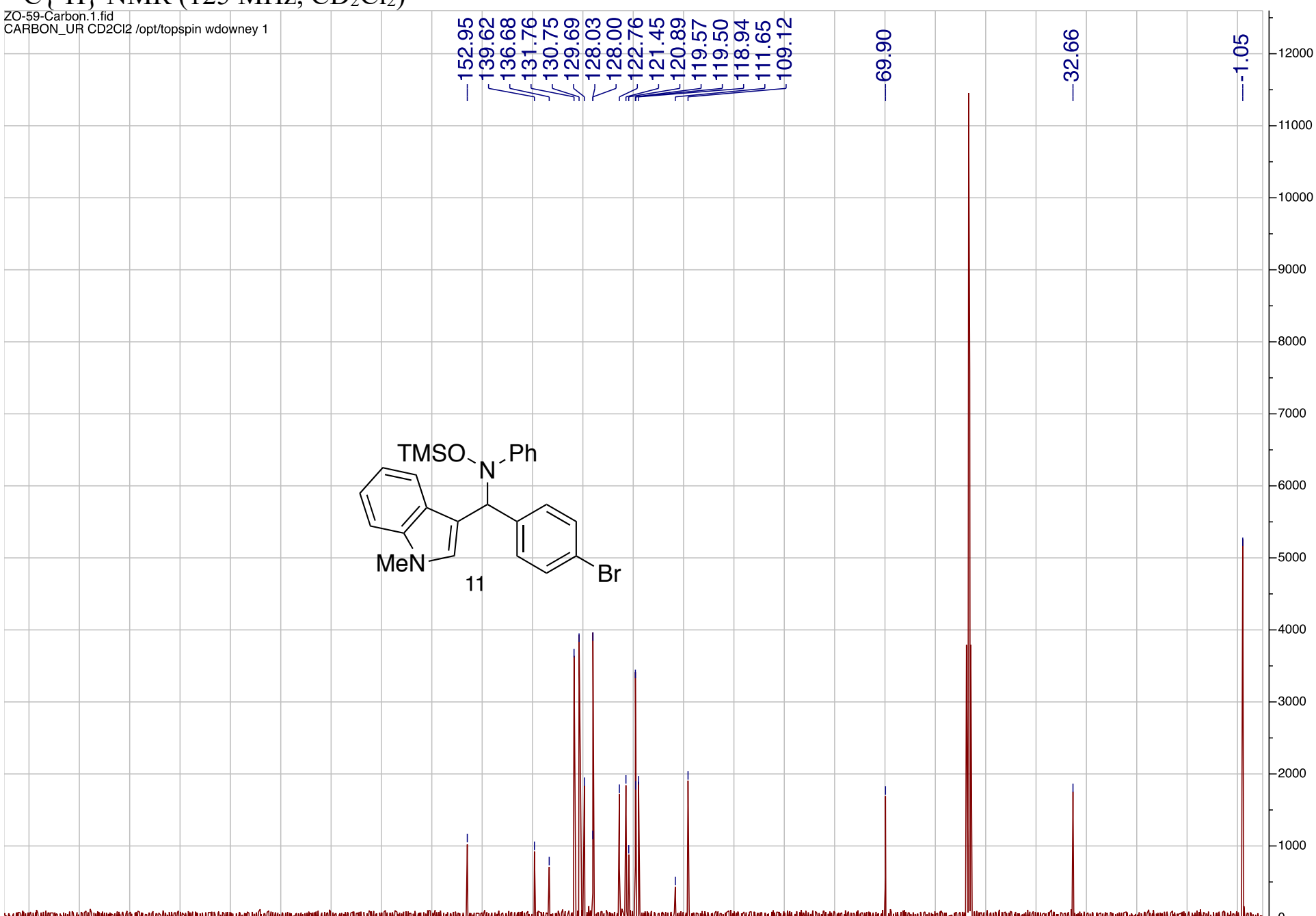

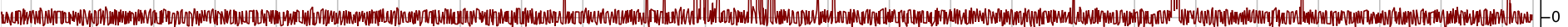

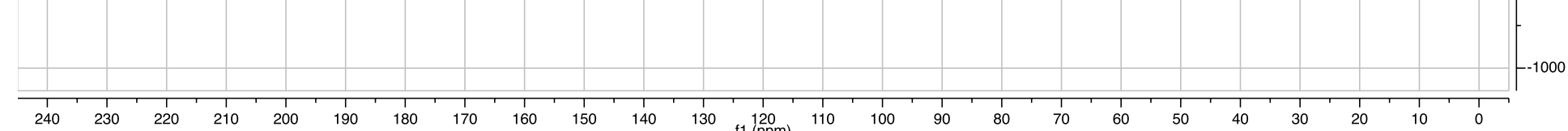


12

${ }^{1} \mathrm{H}$ NMR (300 MHz, $\mathrm{CD}_{2} \mathrm{Cl}_{2}$ )

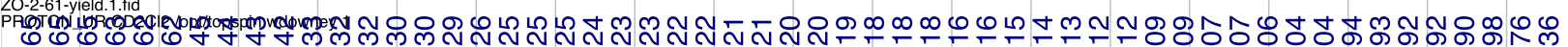

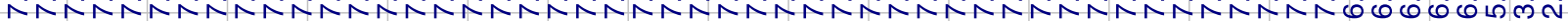

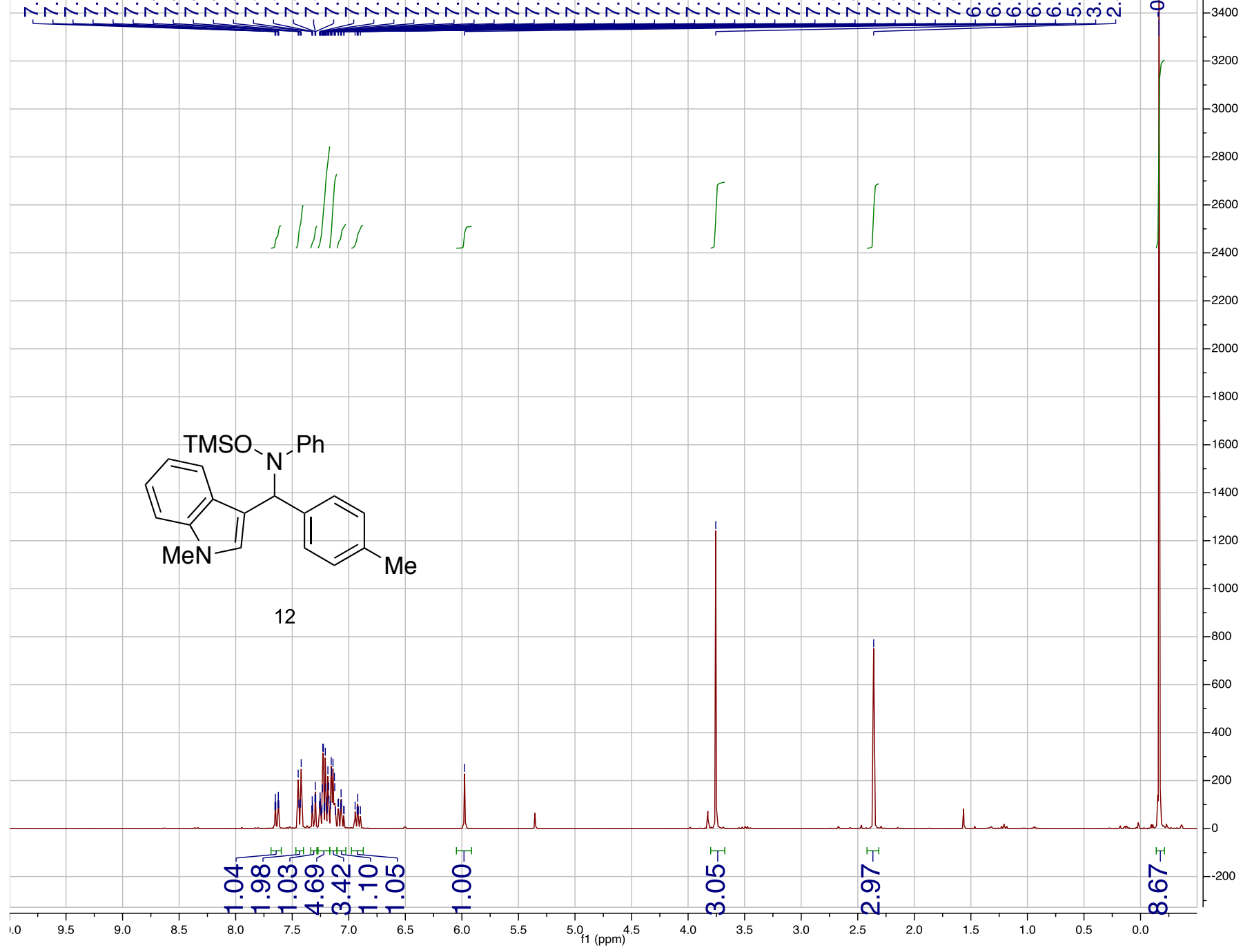




\section{${ }^{13} \mathrm{C}\left\{{ }^{1} \mathrm{H}\right\} \mathrm{NMR}\left(125 \mathrm{MHz}, \mathrm{CD}_{2} \mathrm{Cl}_{2}\right)$}

ZO-2.61-Carbon.1.1fid / loptlopspin wdowney 2

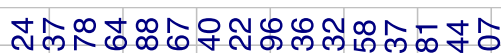

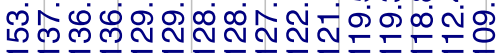

\section{@̊}

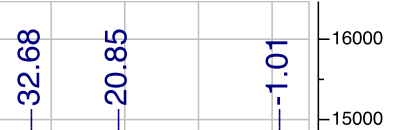

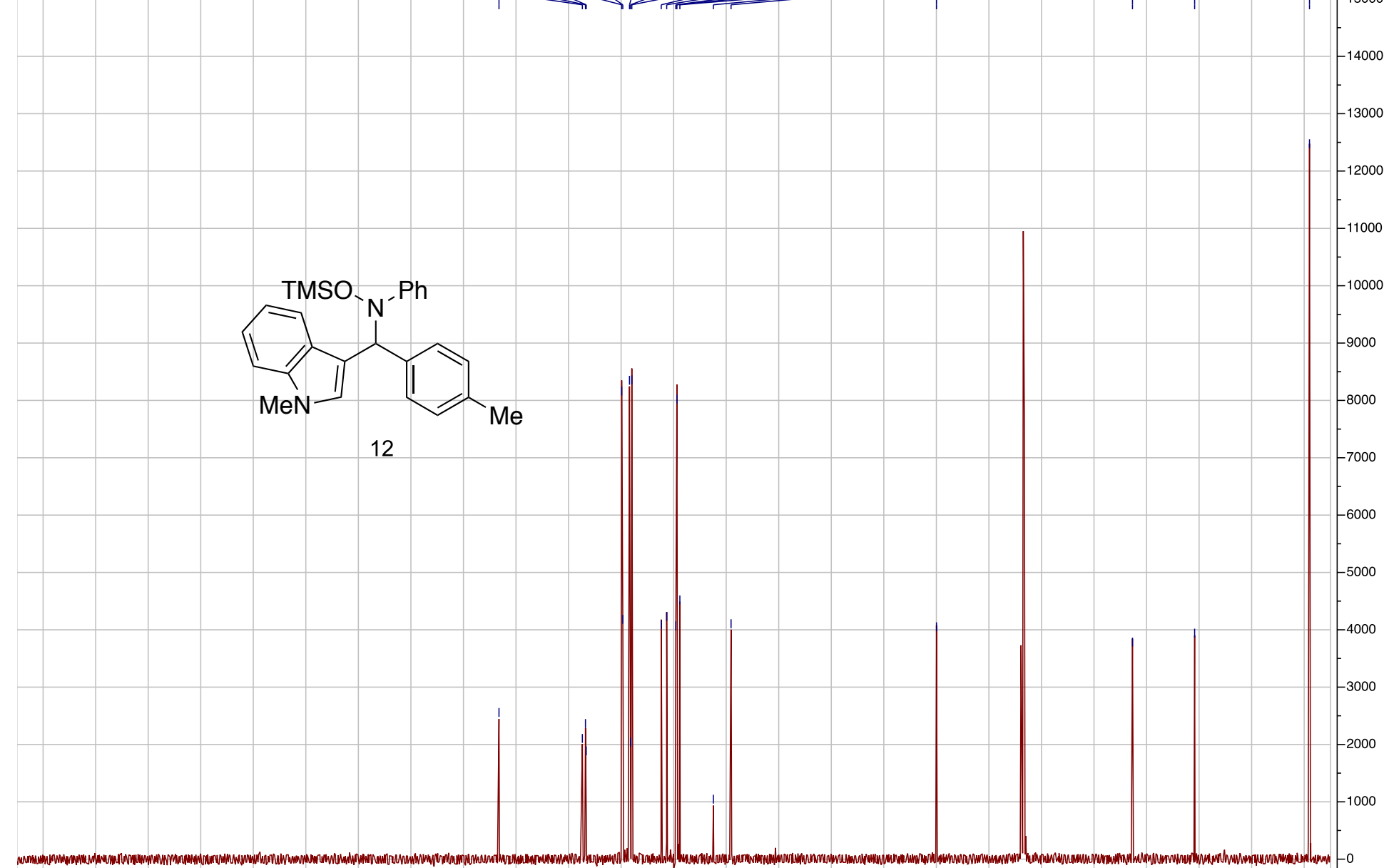
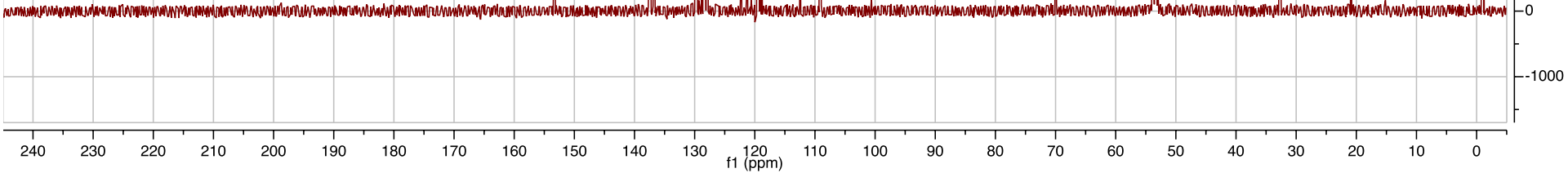
13

${ }^{1} \mathrm{H}$ NMR $\left(300 \mathrm{MHz}, \mathrm{CD}_{2} \mathrm{Cl}_{2}\right)$

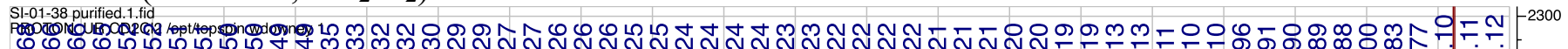

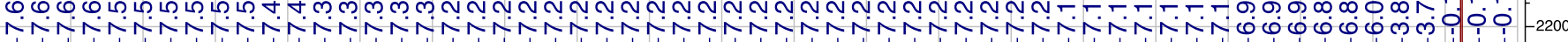

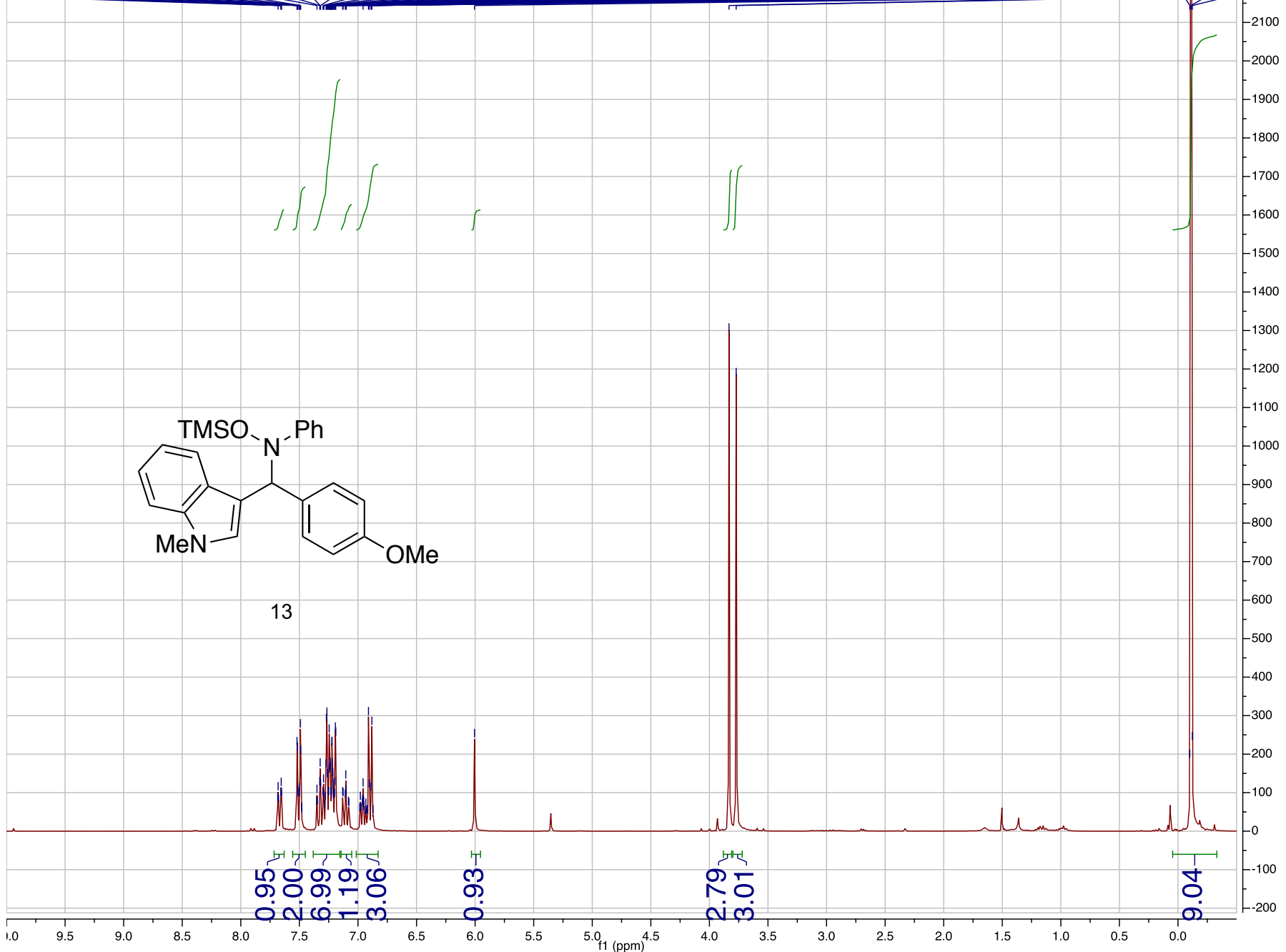


${ }^{13} \mathrm{C}\left\{{ }^{1} \mathrm{H}\right\}$ NMR $\left(100 \mathrm{MHz}, \mathrm{CD}_{2} \mathrm{Cl}_{2}\right)$

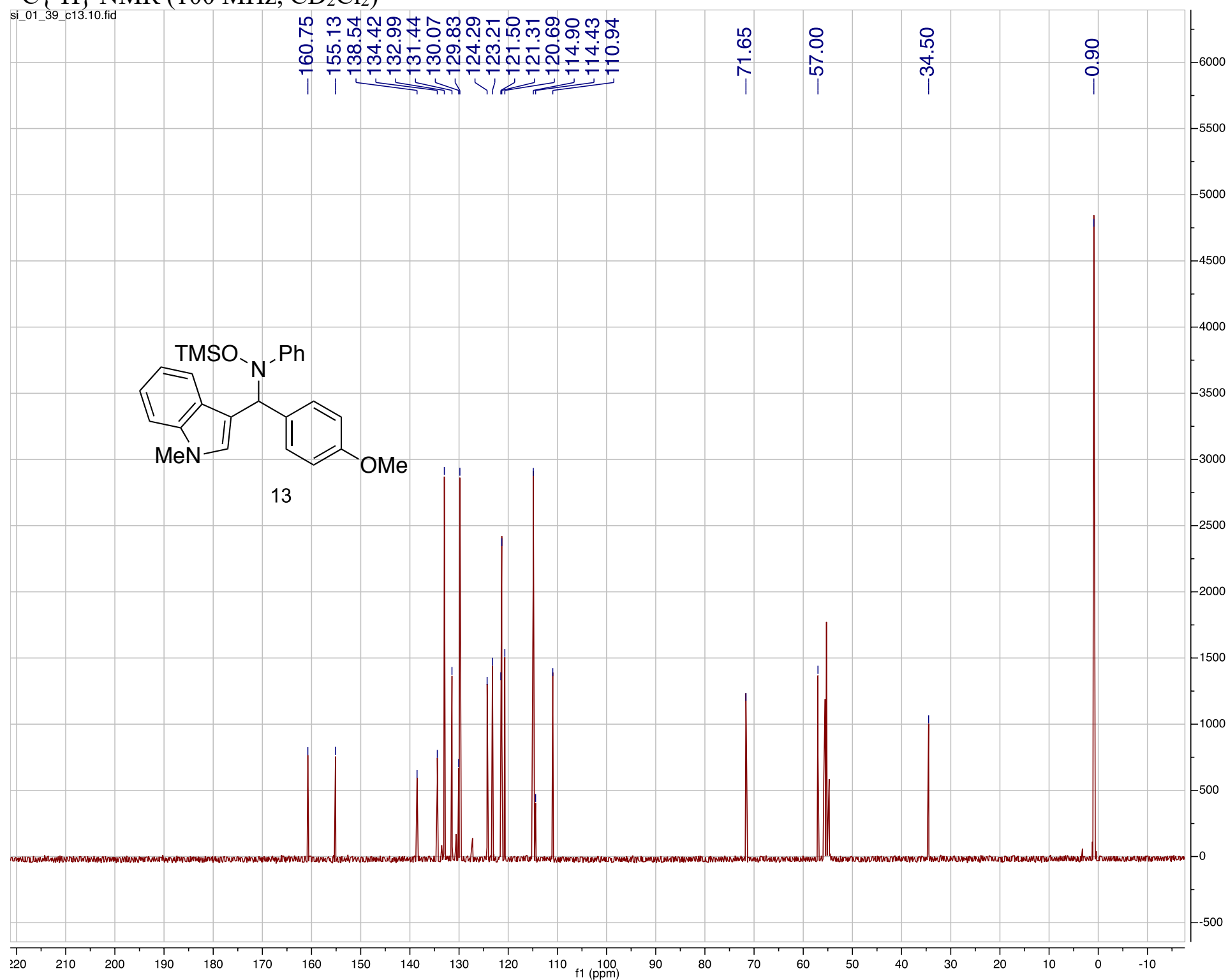


14

${ }^{1} \mathrm{H}$ NMR $\left(500 \mathrm{MHz}, \mathrm{CD}_{2} \mathrm{Cl}_{2}\right)$

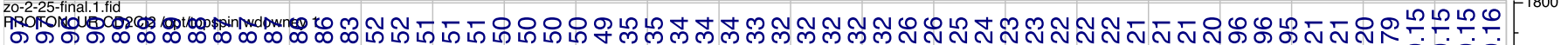

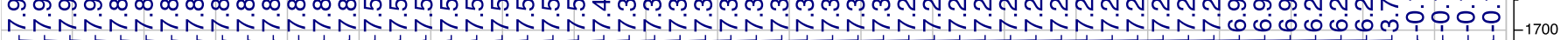

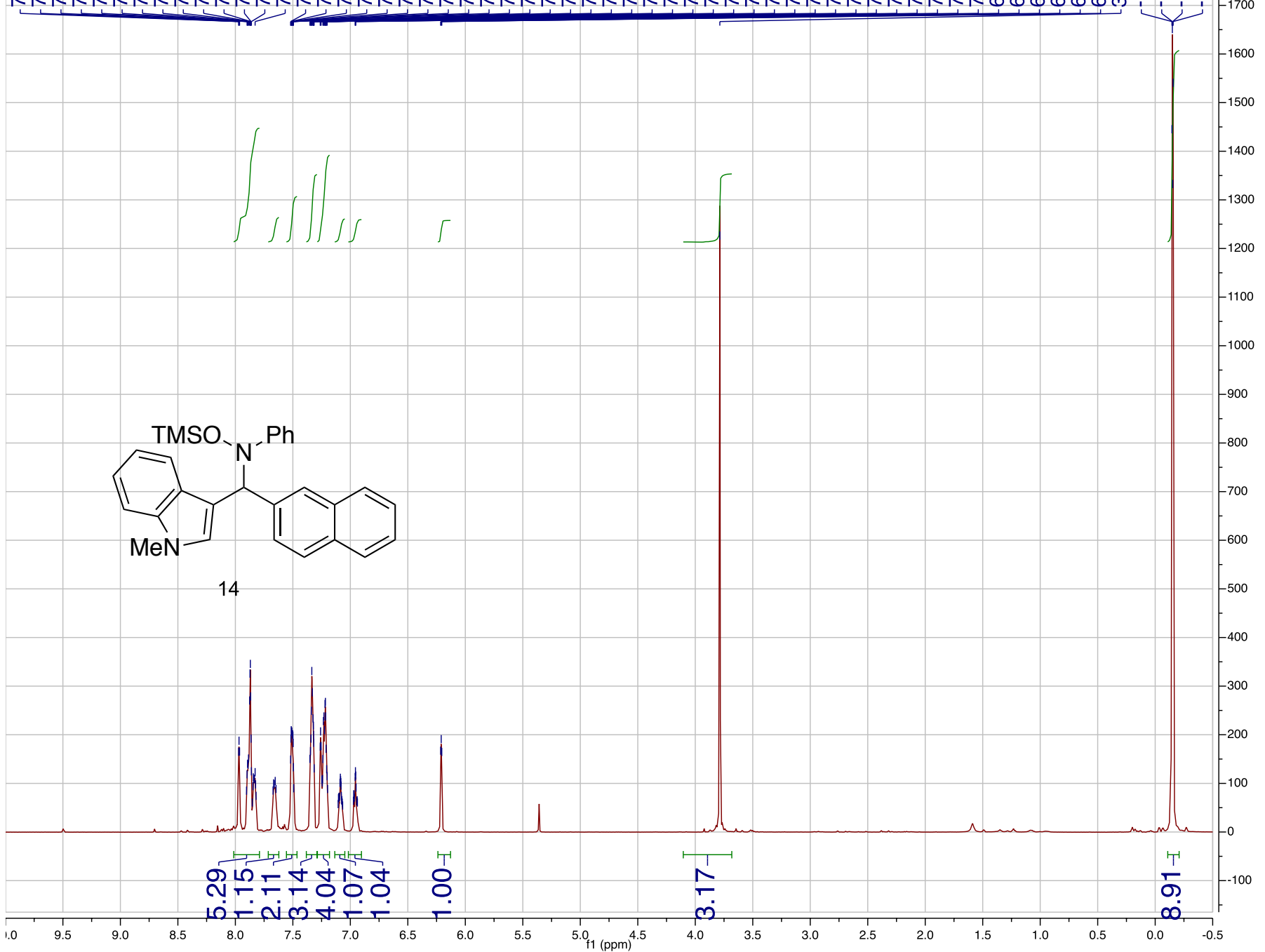


${ }^{13} \mathrm{C}\left\{{ }^{1} \mathrm{H}\right\} \mathrm{NMR}\left(125 \mathrm{MHz}, \mathrm{CD}_{2} \mathrm{Cl}_{2}\right)$

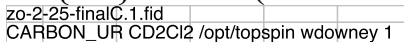

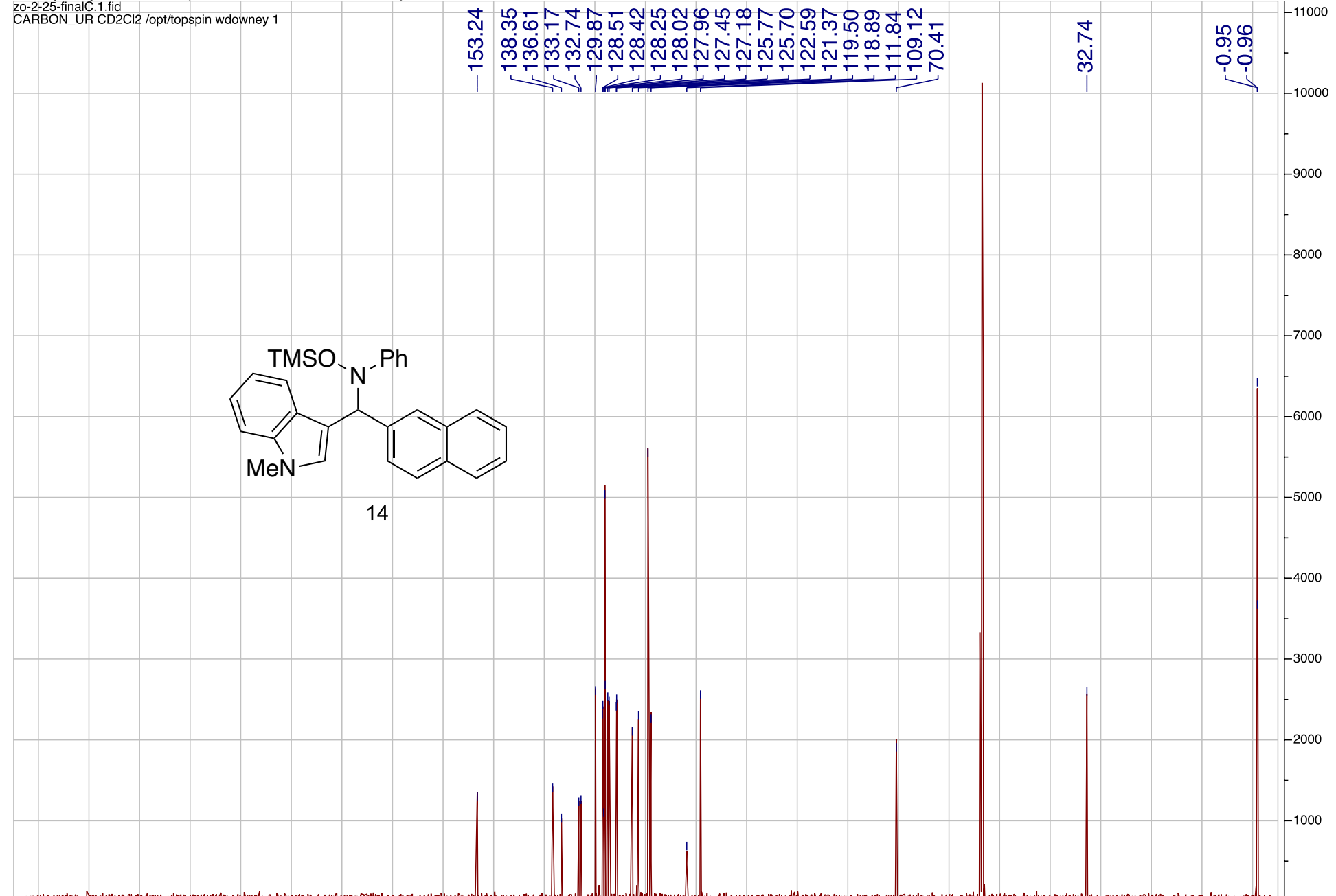

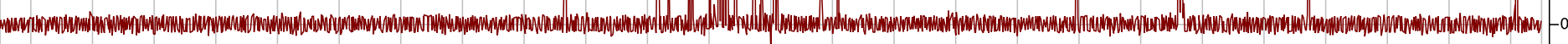

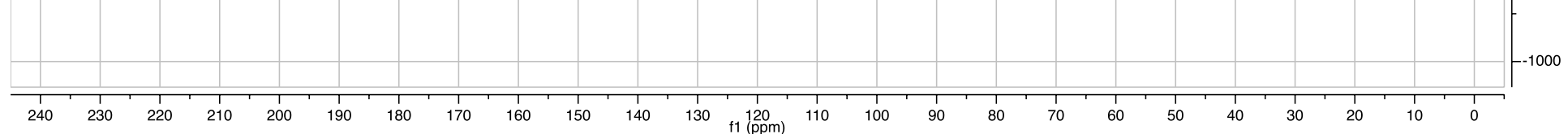


15

${ }^{1} \mathrm{H}$ NMR (500 MHz, $\mathrm{CD}_{2} \mathrm{Cl}_{2}$ )

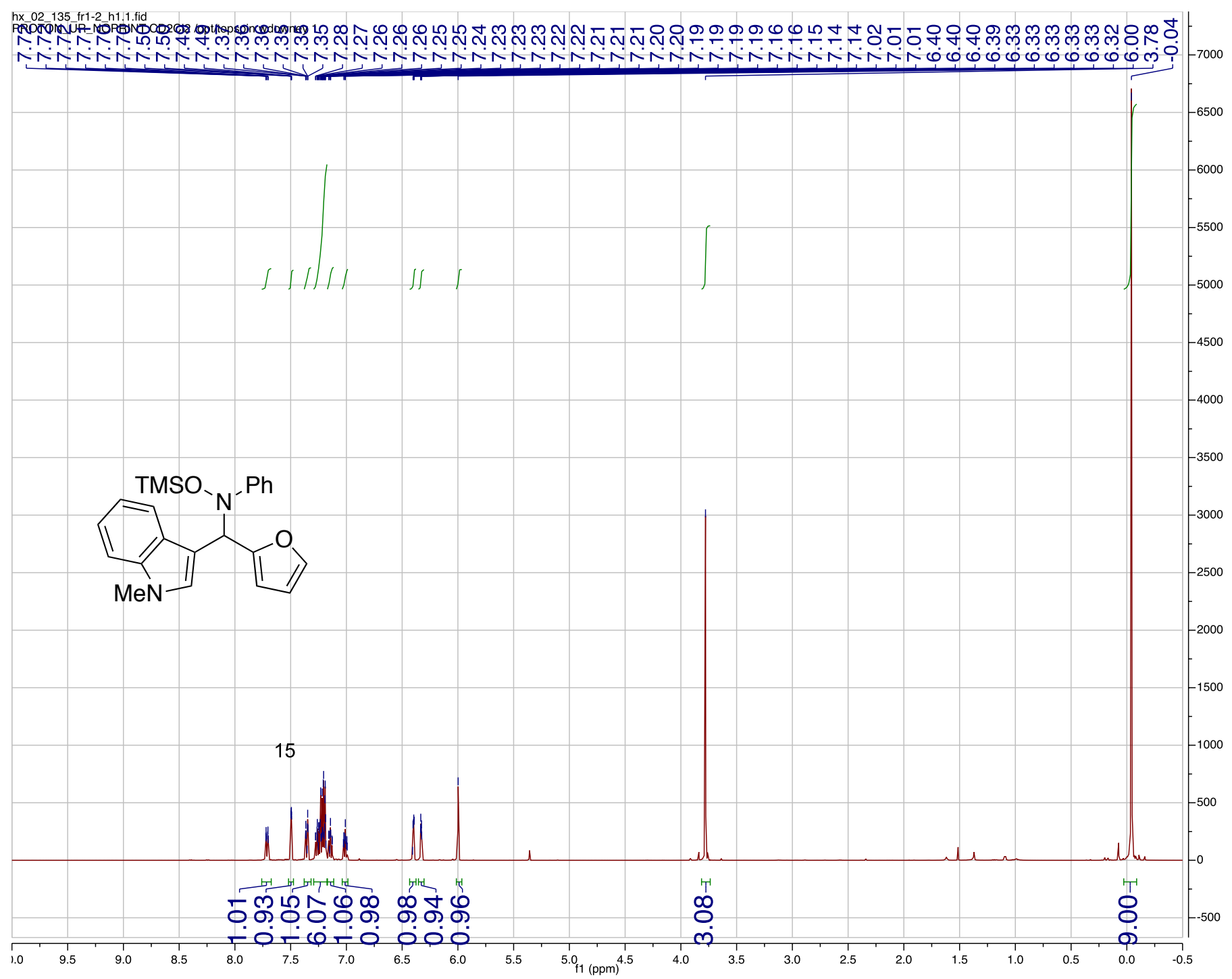




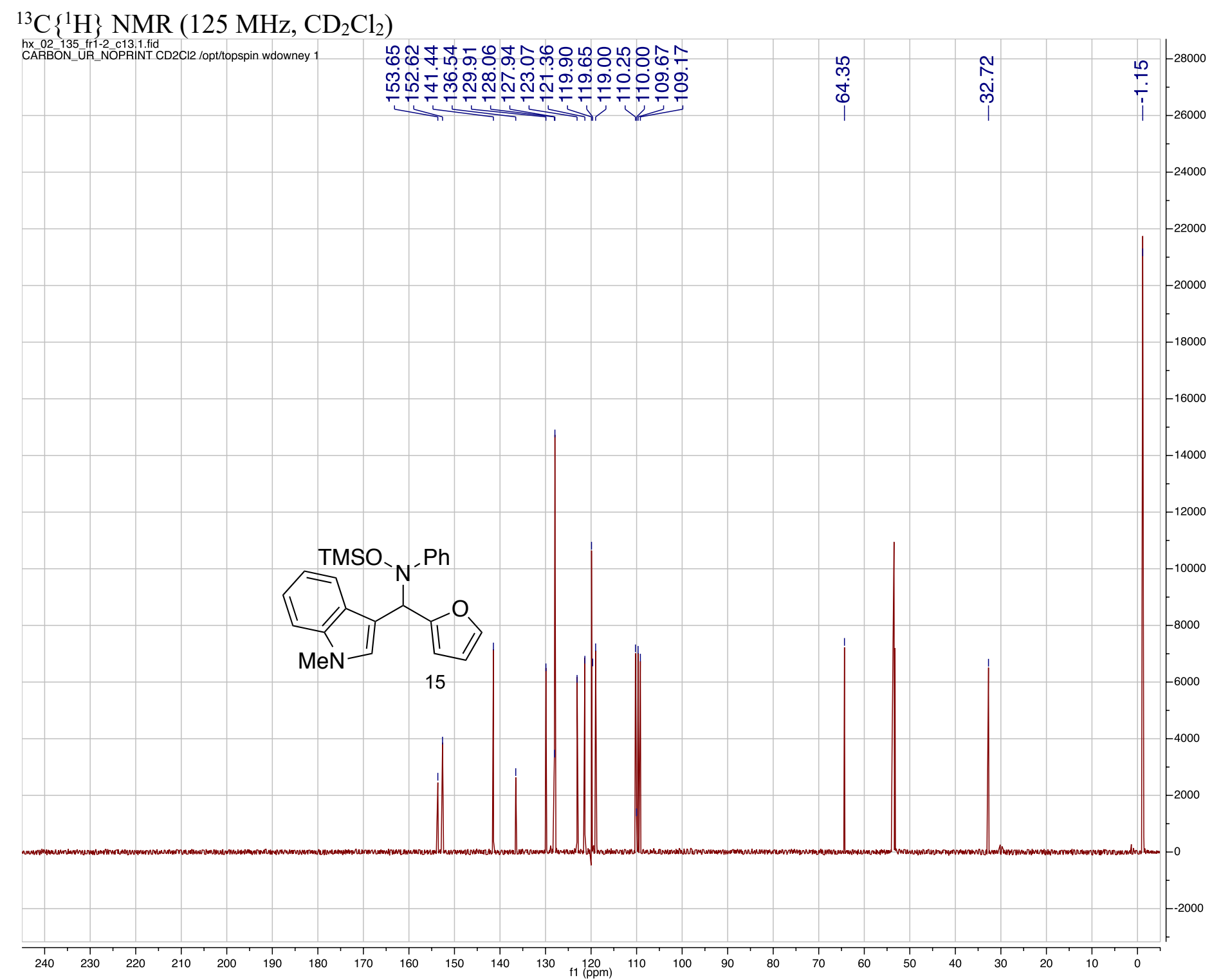


16

${ }^{1} \mathrm{H}$ NMR $\left(500 \mathrm{MHz}, \mathrm{CD}_{2} \mathrm{Cl}_{2}\right)$

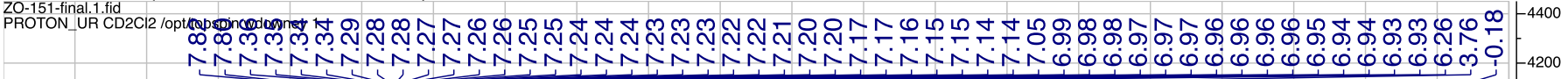

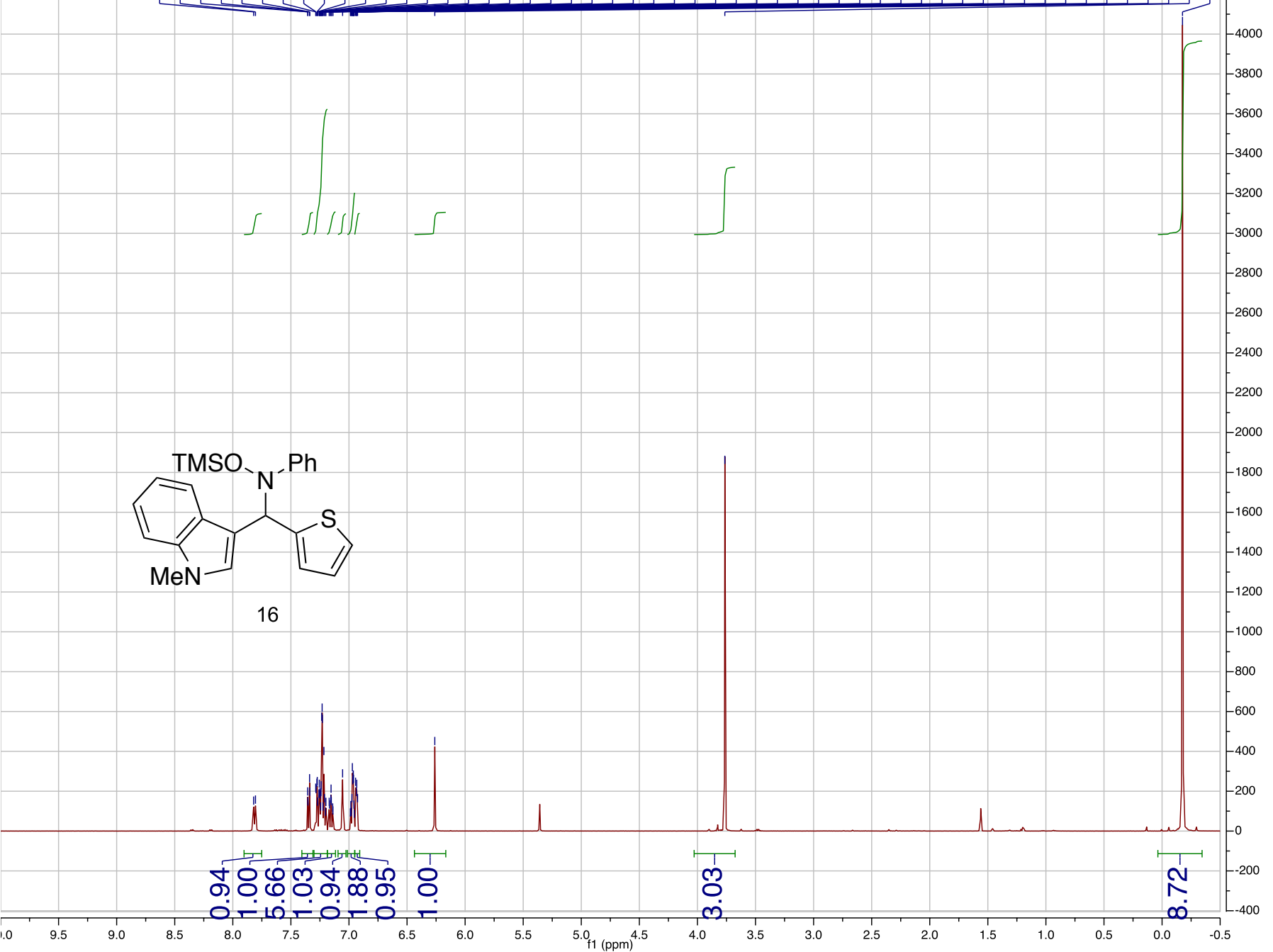




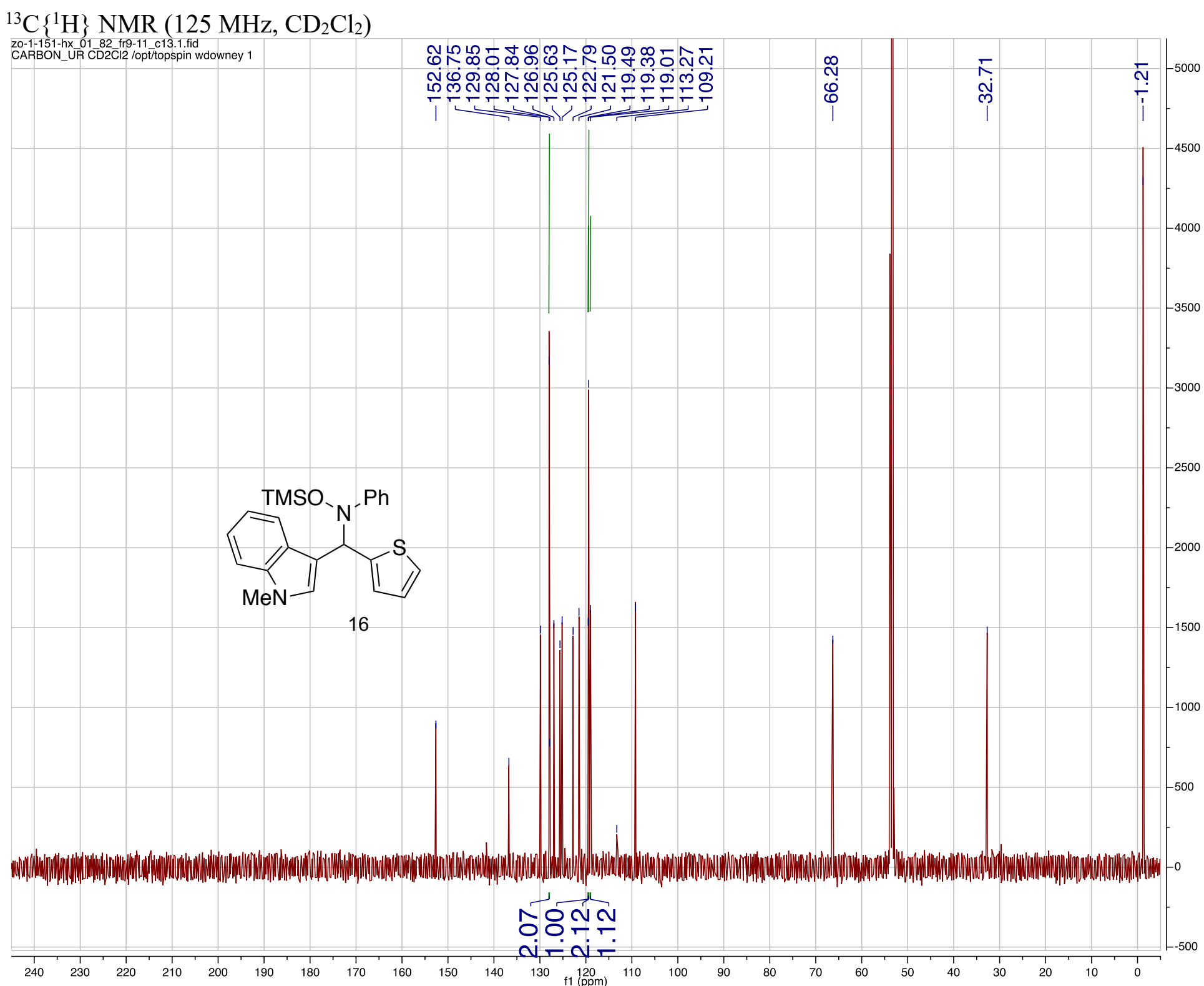


17

${ }^{1} \mathrm{H}$ NMR (300 MHz, $\left.\mathrm{CD}_{2} \mathrm{Cl}_{2}\right)$

Z0-213.tialitid

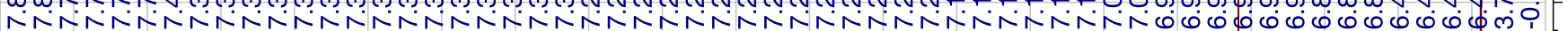

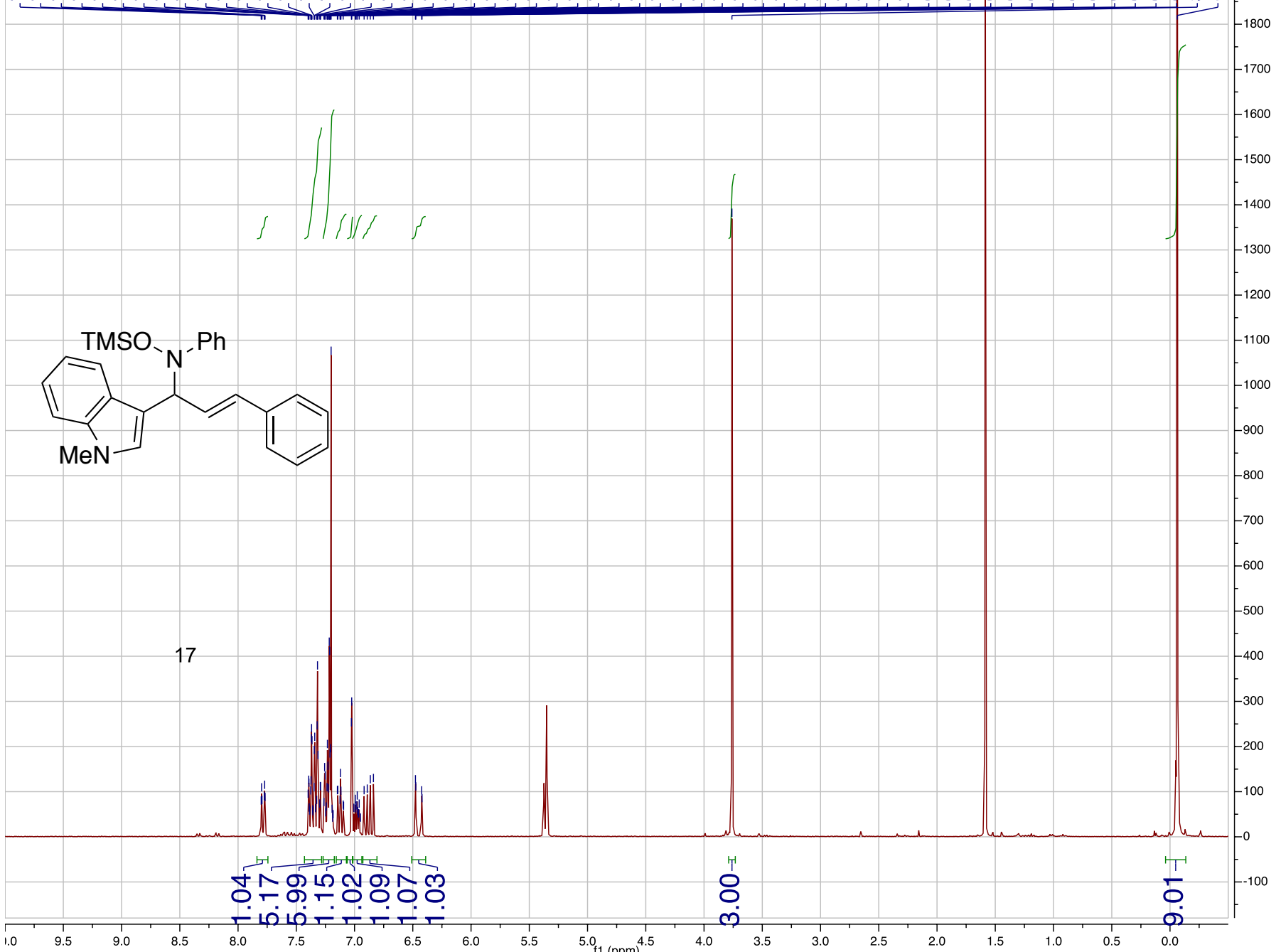


${ }^{13} \mathrm{C}\left\{{ }^{1} \mathrm{H}\right\} \mathrm{NMR}\left(125 \mathrm{MHz}, \mathrm{CD}_{2} \mathrm{Cl}_{2}\right)$

ZO-cinamyl Carbon.1.1fid

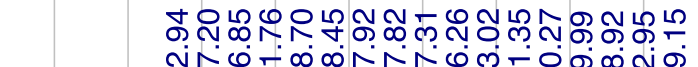

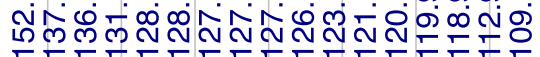

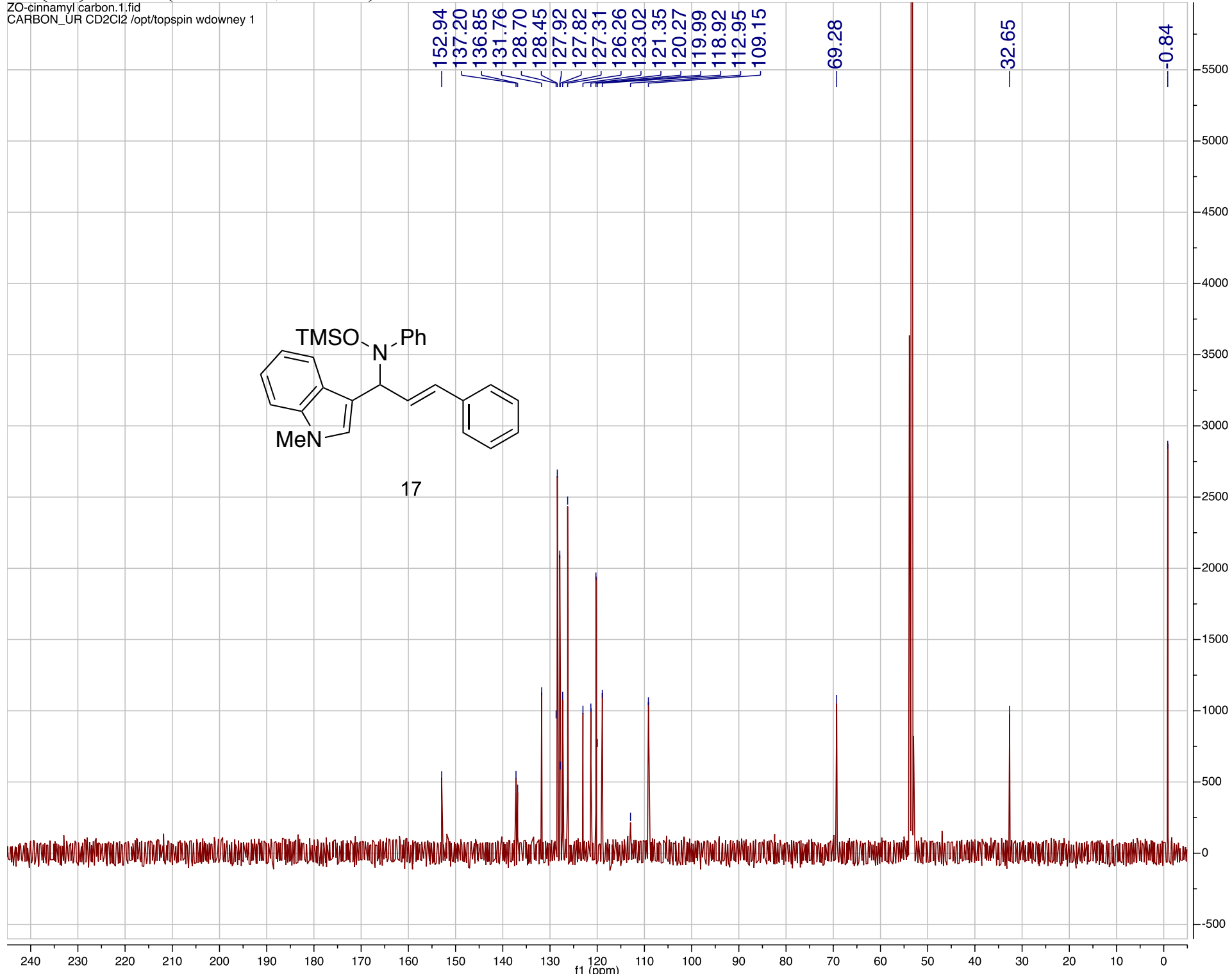

$$
\text { (n) }
$$


18

${ }^{1} \mathrm{H}$ NMR $\left(500 \mathrm{MHz}, \mathrm{CD}_{2} \mathrm{Cl}_{2}\right)$

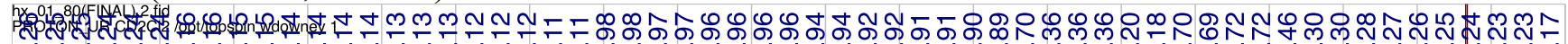

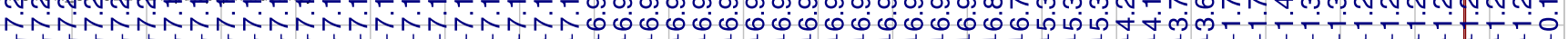

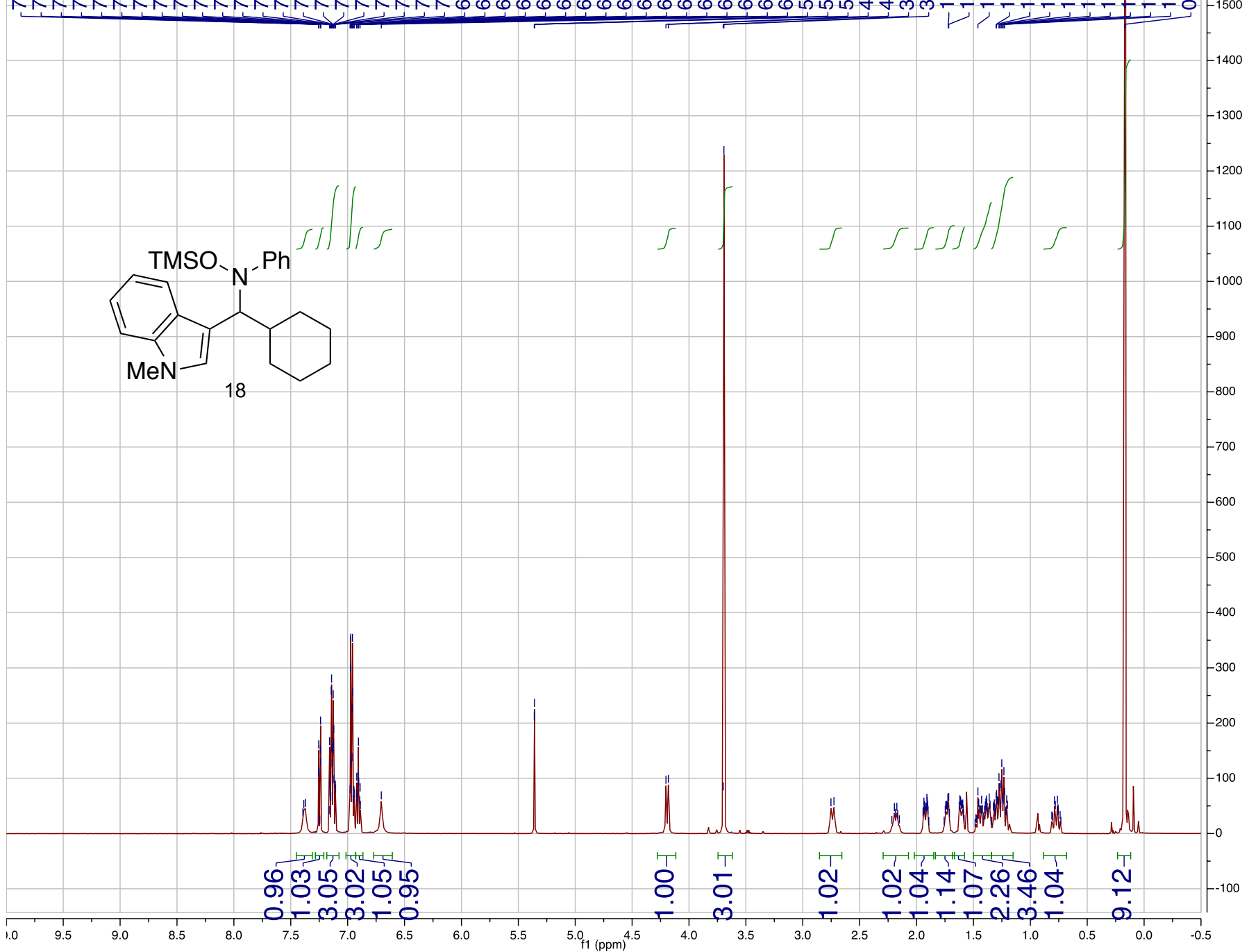


${ }^{13} \mathrm{C}\left\{{ }^{1} \mathrm{H}\right\}$ NMR $\left(125 \mathrm{MHz}, \mathrm{CD}_{2} \mathrm{Cl}_{2}\right)$

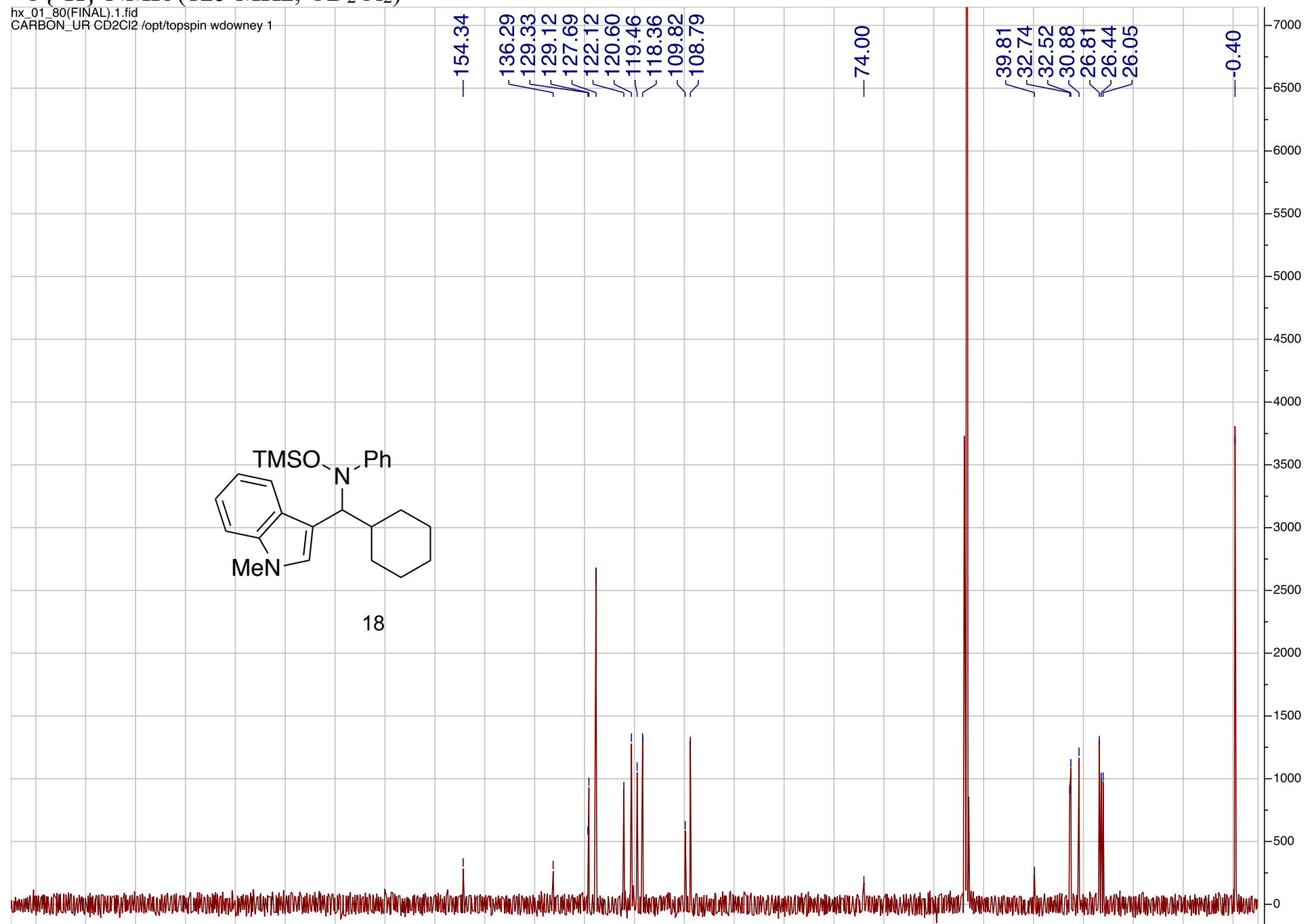

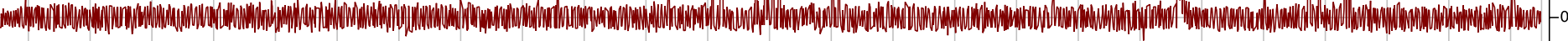

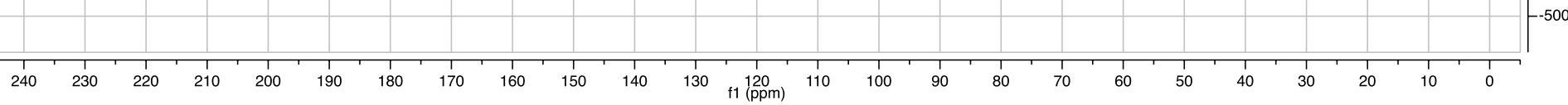

